Integrating NASA Earth Science Capabilities into the Interagency Modeling and Atmospheric Assessment Center for Improvements in Atmospheric Transport and Dispersion Modeling

M. D. Simpson, M. F. Jasinski, J. Borak, S. Blonski, J. Spruce, H. Walker, L. Delle Monache

October 30, 2012 
This document was prepared as an account of work sponsored by an agency of the United States government. Neither the United States government nor Lawrence Livermore National Security, LLC, nor any of their employees makes any warranty, expressed or implied, or assumes any legal liability or responsibility for the accuracy, completeness, or usefulness of any information, apparatus, product, or process disclosed, or represents that its use would not infringe privately owned rights. Reference herein to any specific commercial product, process, or service by trade name, trademark, manufacturer, or otherwise does not necessarily constitute or imply its endorsement, recommendation, or favoring by the United States government or Lawrence Livermore National Security, LLC. The views and opinions of authors expressed herein do not necessarily state or reflect those of the United States government or Lawrence Livermore National Security, LLC, and shall not be used for advertising or product endorsement purposes.

This work performed under the auspices of the U.S. Department of Energy by Lawrence Livermore National Laboratory under Contract DE-AC52-07NA27344. 


\title{
Integrating NASA Earth Science Capabilities into the Interagency Modeling and Atmospheric Assessment Center for Improvements in Atmospheric Transport and Dispersion Modeling
}

\author{
Final Project Report
}

\author{
Matthew Simpson ${ }^{1}$ \\ Michael F. Jasinski ${ }^{2}$ \\ Jordan Borak ${ }^{2}$ \\ Slawomir Blonski ${ }^{3}$ \\ Joe Spruce ${ }^{3}$ \\ Hoyt Walker ${ }^{1}$ \\ Luca Delle Monache ${ }^{4}$ \\ (1) Lawrence Livermore National Laboratory (LLNL) \\ (2) NASA Goddard Space Flight Center \\ (3) Stennis Space Center \\ (4) National Center for Atmospheric Research
}

September 2012

(Final Version released 30 October 2012)

This work was performed under the auspices of the U.S. Department of Energy by Lawrence Livermore National Laboratory under Contract DE-AC52-07NA27344. LLNL-TR-596732. 


\section{Executive Summary}

This report describes the development of algorithms to derive accurate surface roughness and displacement height values from NASA satellite data for both urban and vegetation environments and to evaluate the potential benefit of improved surface data characterization on atmospheric transport and dispersion modeling. One of the key factors limiting the accuracy of near-surface wind profile modeling and dispersion simulations is the lack of location-specific and seasonally-dependent surface characteristic values. Currently, land use category look-up tables are commonly used to provide grid-cell estimates of surface characteristics values, even though surface roughness values can vary significantly within the same land-use category. This report documents: i) the derivation of surface characteristic values by Goddard Space Flight Center (GSFC) and Stennis Space Center (SSC) from NASA satellite multispectral imagery, ii) their incorporation into atmospheric meteorological and transport models, and iii) the results of a dispersion modeling study for Oklahoma City and the surrounding region to evaluate the impact of GSFC/SSC roughness on National Atmospheric Release Advisory Center (NARAC) / Interagency Modeling and Atmospheric Assessment Center (IMAAC) emergency response dispersion predictions.

The NASA satellite derived surface data evaluation study is performed based on the following steps:

- Extension of recently developed and published GSFC/SSC methodologies to generate urban and non-urban surface roughness and displacement height fields covering the continental United States by utilizing NASA Moderate Resolution Imaging Spectroradiometer (MODIS), Landsat, and Shuttle Radar Topography Mission (SRTM) satellite data

- Generation of combined urban and non-urban surface characteristics data fields for NARAC/IMAAC dispersion sensitivity simulations over a research domain centered over Oklahoma City

- Development of a capability to ingest GSFC/SSC-provided surface roughness and displacement height fields into the NARAC/IMAAC modeling system

- Investigation of the sensitivity of atmospheric transport and dispersion predictions to incorporation of GSFC/SSC-derived surface roughness fields by simulating both CONTROL dispersion runs (using default NARAC/IMAAC surface data parameter values) and NASADATA runs (which use both NASA satellite derived surface roughness and displacement height fields)

- Formulation of recommendations on future work to further evaluate the potential benefits of using NASA surface roughness products in dispersion modeling decision support tools 


\section{Conclusions}

The scientific conclusions resulting from the data evaluation study are summarized below:

- A systematic difference in GSFC/SSC roughness lengths for rural land use is observed over the Oklahoma City research domain, with CONTROL values predominantly higher than NASADATA by around 0.05 to $0.1 \mathrm{~m}$ for crop and grassland and up to $0.45 \mathrm{~m}$ for deciduous forest land use. The typical difference between CONTROL and GSFC/SSC urban roughness lengths is between -0.2 to $0.5 \mathrm{~m}$ with CONTROL values predominately larger.

- Use of GSFC/SSC surface characteristic values derived from NASA satellite data decreases simulated near surface wind speeds in rural areas by around $0.25 \mathrm{~m} / \mathrm{s}$ and increases surface layer wind speeds at heights between $15 \mathrm{~m}$ and $130 \mathrm{~m}$ by 0.25 to $0.75 \mathrm{~m} / \mathrm{s}$. Simulated nearsurface wind speeds in urban areas are significantly influenced by using GSFC/SSC surface roughness and displacement height values. CONTROL run urban wind speeds below a height of $10 \mathrm{~m}$ are frequently 0.5 to $1.0 \mathrm{~m} / \mathrm{s}$ less than those generated based on NASADATA surface data. Simulated wind speeds at heights between 10 and $130 \mathrm{~m}$ often increase by a few meters per second when using GSFC/SSC-derived surface data.

- Different statistical metrics of dispersion prediction skill indicate comparable performance between CONTROL and NASADATA runs. Runs based on CONTROL default surface parameter values provide the best dispersion results based on the standard fraction of predicted values within a factor or 2, 5, and 10 of the observed concentration (FAC2, FAC5, and FAC10) and the geometric mean (MG) while NASADATA runs perform better based on normalized mean square error (NMSE) and fractional bias (FB). The lack of consistency between these statistical metrics implies there is no clear better source of surface data parameters for this dispersion evaluation study and that both sets of runs exhibit the same general level of dispersion prediction skill.

- Predicted peak air concentrations are highly sensitive to surface roughness and displacement height values with CONTROL run peak concentrations between 35 and 49\% lower than NASADATA peak simulated concentrations.

- Centerline air concentrations in rural areas downwind of an urban release location are marginally sensitive to the choice of surface roughness data with most CONTROL and NASADATA prediction differences within 10\%. However, the JU2003 data do not extend far enough downwind for differences in rural surface roughness values to be fully evident. One dispersion test case examined demonstrates a particular sensitivity to roughness data and warrants additional analysis.

- The CONTROL runs in this evaluation study use surface characteristics derived from OKC building data that have been shown to give excellent results for JU2003 dispersion studies (Delle Monache 2009). Therefore, the NASADATA runs are being compared against a model configuration already shown to perform exceedingly well for the JU2003 test cases. The 
comparable dispersion prediction skill shown by the CONTROL and NASADATA runs support the conclusion that GSFC and SSC have developed a robust methodology for determining surface characteristics from NASA satellite data.

\section{Recommendations}

Based on the data evaluation study, we conclude that GSFC and SSC have developed a robust methodology for determining surface roughness. The new satellite-derived surface data capability has the potential to improve numerical weather prediction (NWP) accuracy and dispersion modeling, especially in modeling peak concentrations. Additional evaluation of the impacts of GSFC/SSC surface data is needed to fully assess the locations and scenarios where such surface data are likely to provide the greatest value. Specifically, the additional follow-on studies are recommended:

- Evaluation of GSFC/SSC surface data impact in urban centers with different building geometries and densities to confirm the results from this project

- Investigation of impacts due to seasonal surface roughness variation particularly for rural areas

- Study the impact of GSFC/SSC data on dispersion model concentrations over larger geographic scales where the uncertainty associated with surface data values is expected to have a greater impact than on near-source plume concentrations 


\section{Table of Contents}

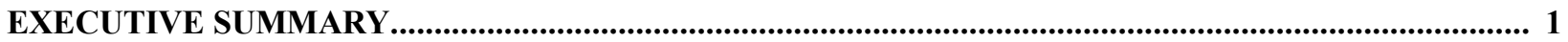

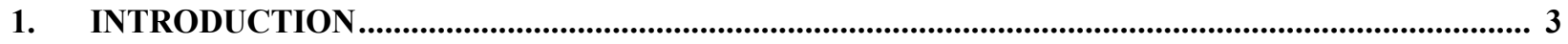

1.1 BACKGROUND

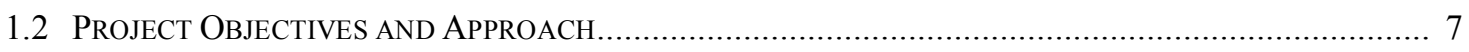

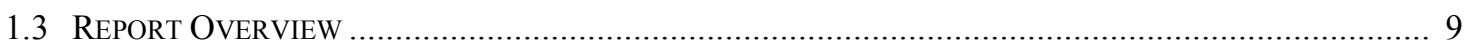

2. GSFC/SSC SURFACE CHARACTERISTIC DATA …..................................................................... 10

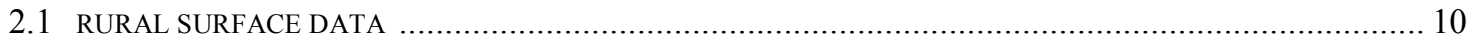

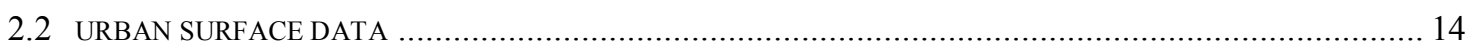

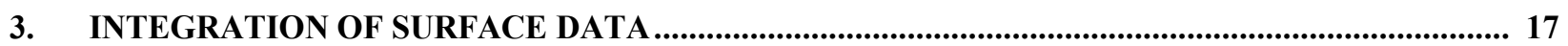

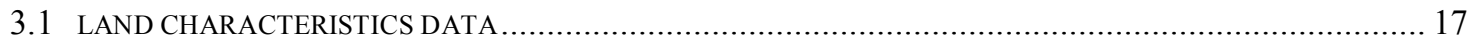

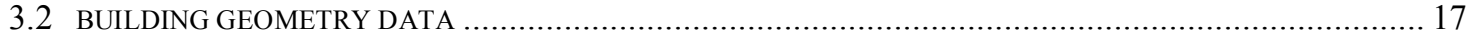

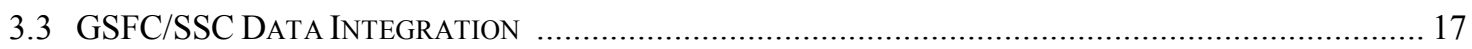

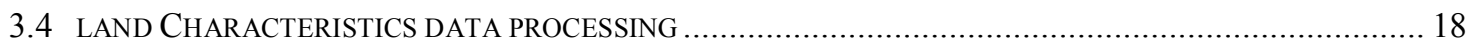

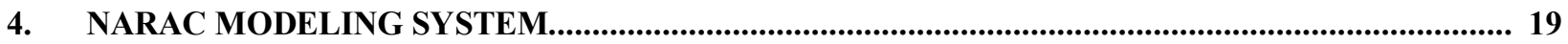

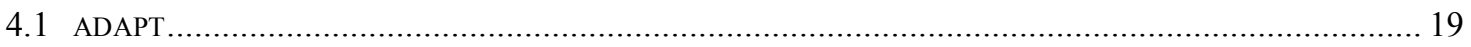

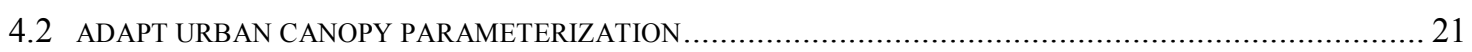

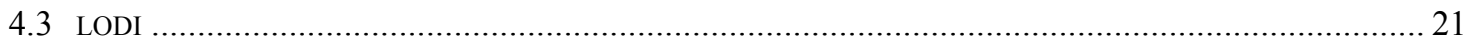

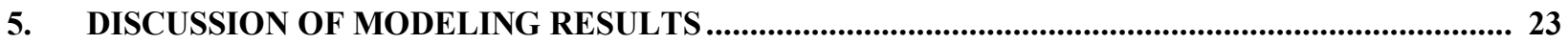

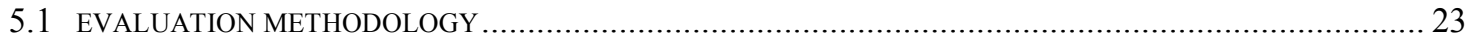

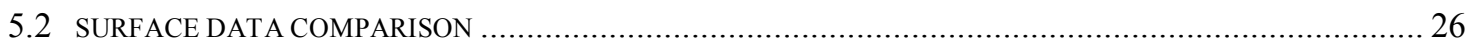

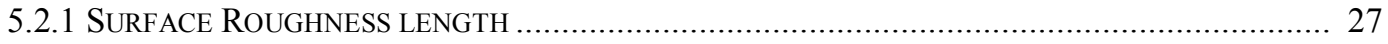

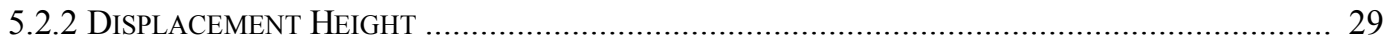

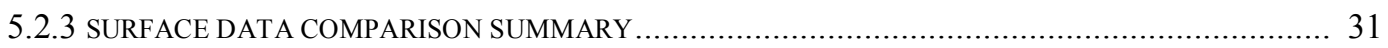

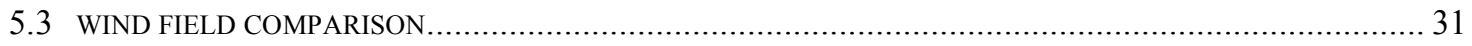

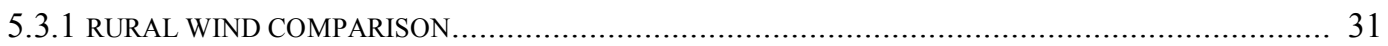

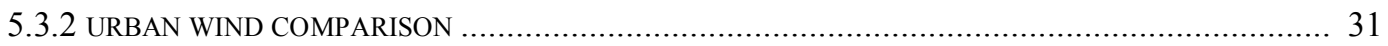

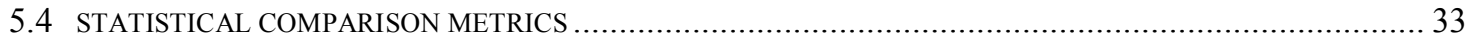

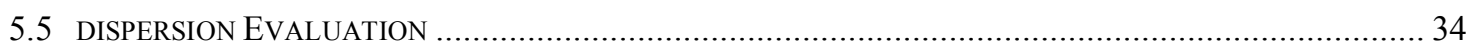

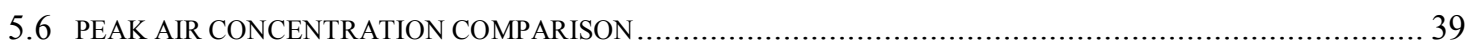

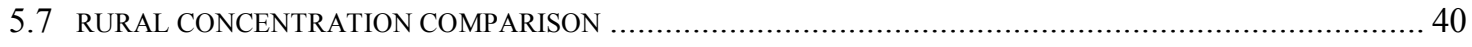

6. SUMMARY OF EVALUATION STUDY RESULTS ...................................................................... 44

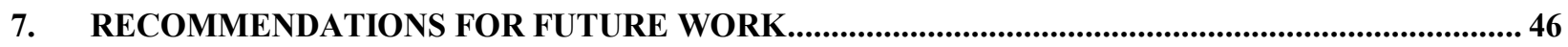

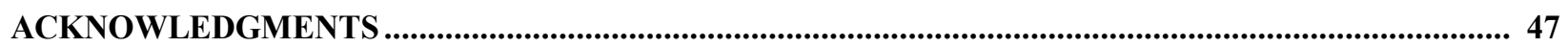

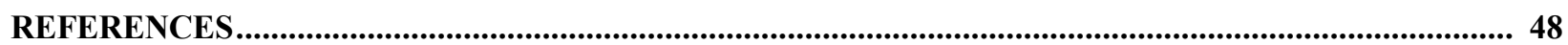

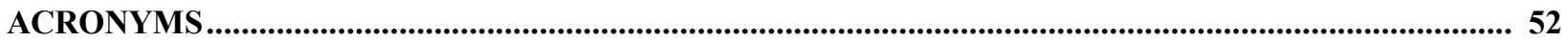

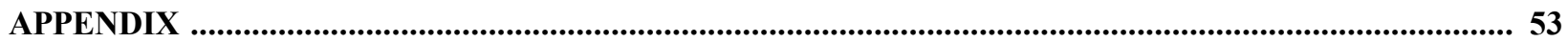




\section{Introduction}

\subsection{Background}

Near-surface vertical wind profiles and turbulent mixing are significantly influenced by surface characteristics. Two of the most common parameters used to account for surface stress on modeled wind fields are the surface roughness length scale and the zero-plane displacement height. The roughness length defines the height above the surface where the mean horizontal wind speed becomes zero due to frictional forces. The zero-plane displacement height is used to account for the enhanced momentum sink created by dense vegetation or urban canopies and to preserve the validity of the surface layer wind profile described by the logarithmic wind profile equation.

Roughness lengths are proportional to the physical height of surrounding obstacles that interact with and disrupt the mean wind. Regions with no dominant obstacles such as the calm ocean and snow-covered flat plains have the lowest roughness length values of around $0.0002 \mathrm{~m}$ (Wieringa 1992). Areas with tall obstacles such as forests and urban areas with tall buildings have the highest roughness length heights of around 1 - $3 \mathrm{~m}$ (Schnelle and Dey 1999). Croplands typically have roughness length values between 0.04 to $0.25 \mathrm{~m}$, while grasslands have roughness lengths around 0.003 to $0.1 \mathrm{~m}$ (Smith 1993, USEPA 2001). Surface roughness length is not a parameter that is directly measured and no specific guideline currently exists for determining highly accurate values. Spatially-varying and seasonal-dependent roughness values for atmospheric dispersion modeling are typically assigned based on the land-use category at each model grid cell. Although land-use look-up tables provide reasonable estimates of roughness lengths, default values should be considered as general guidance only since surface roughness length can vary significantly within the same land-use category (VicEPA 2000). Uncertainty associated with roughness length values is an area of scientific interest since surface roughness is a critical input parameter to the logarithmic wind profile equations that are used by atmospheric models to simulate the mean wind speed profile in the surface layer (Stull 1993).

Raupach and Thom (1981) define the zero-plane displacement height as the mean height above ground where momentum is absorbed by a canopy. Jackson (1981) has shown that the displacement height coincides with the mean displacement thickness for shear stress terms in the equations of motion. Figure 1 shows a theoretical wind speed profile in the presence of a dense vegetation canopy. Winds above the forest canopy increase logarithmically according to the log wind profile, with the level determined by the displacement height (d) plus the roughness length $\left(z_{0}\right)$ defining the height where the logarithmic wind profile above the canopy goes to zero. The net effect of the displacement height is to shift the logarithmic wind profile upwards proportional to the height of the canopy layer. Displacement heights associated with forest canopies are typically estimated as between 0.6 and 0.8 times the height of the canopy (Arya 1998; Stull 1993). Hanna and Chang (1992) recommend the use of urban displacement heights based on 0.5 times the grid-cell average building heights. Methods to calculate displacement heights are an important research topic since accurate displacement height values are critical to modeling wind profiles in the presence of tall canopies (Dong 2001). 


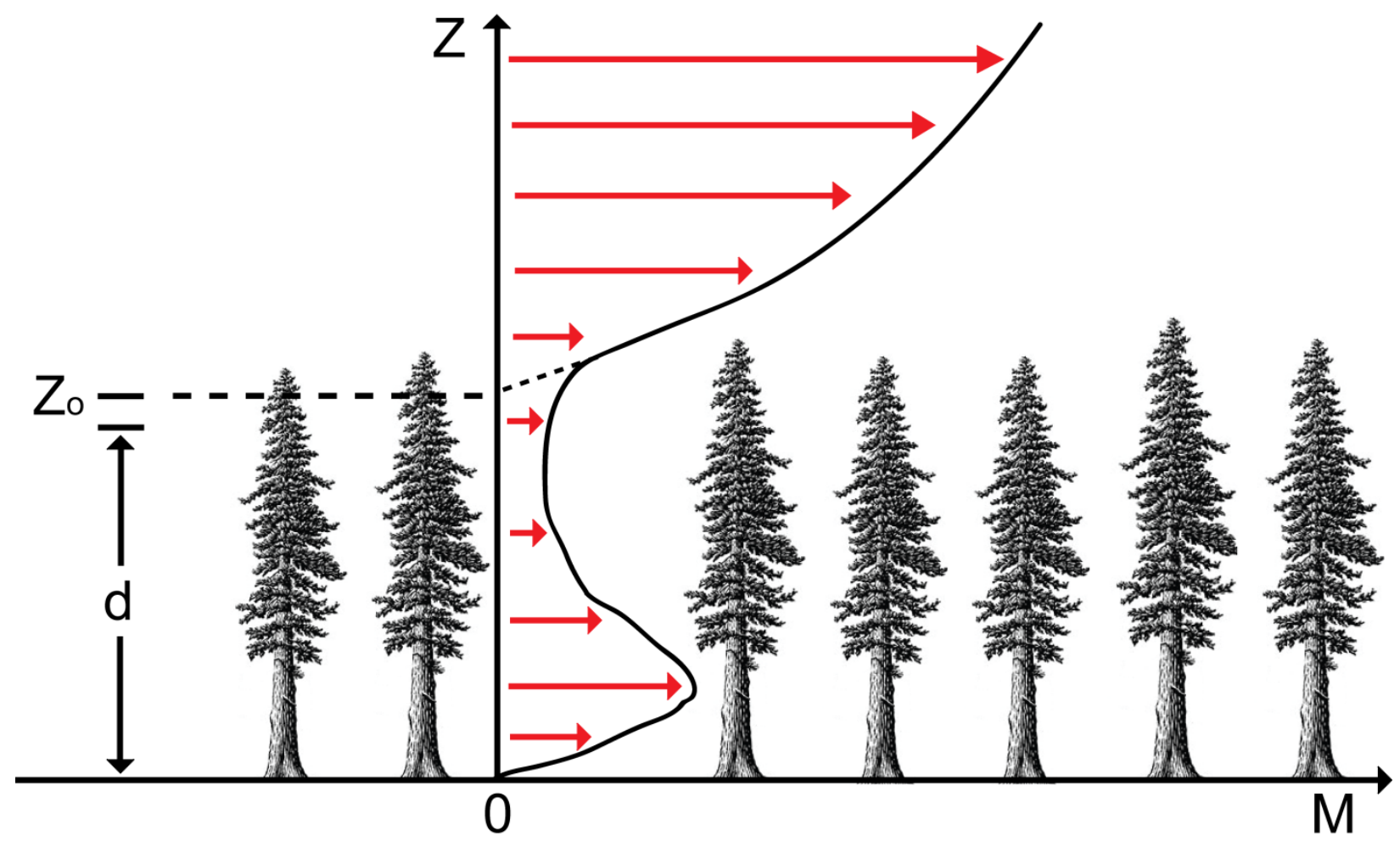

Figure 1. Theoretical vertical wind profile over a dense vegetation canopy. The wind speed increases logarithmically with height above the level of the displacement height (d) plus the roughness length $\left(\mathrm{Zo}_{\mathrm{o}}\right.$. The M-axis shows the relative wind speeds. Figure based on Stull 1993.

Numerous studies indicate surface roughness and displacement height values may have a large impact on wind flow and dispersion modeling. During neutral and stable atmospheric conditions, surface roughness is the dominant contributor to mechanical turbulence generation that in return modifies near surface wind profiles and increases the vertical mixing of a plume (VicEPA 2000). Increased surface roughness is shown to weaken simulated near-surface wind speeds associated with a tropical storm making landfall (Zhu 2008). Wever (2012) showed higher surface roughness values in the Netherlands resulting from increased urbanization, forest area, and agricultural land, with tall cropland exhibiting a decrease in observed mean wind speeds by around $3.1 \%$ per decade since the early eighties. Surface roughness anomalies modify regional climates by altering low-level convergence and divergence patterns which in return influence temperature advection (Kirk-Davidoff and Keith 2008). Previous research also has shown downwind dispersion modeling results are highly sensitive to variations in surface roughness (Harris et al., 1996). Grosch (1999) found predicted air concentrations from the AERMOD regulatory dispersion model were most sensitive to surface roughness among the list of possible land use / land cover parameters. In a separate study, predicted concentrations from elevated, ground-level point and volume source releases were found to be sensitive to variations in surface roughness values (Long 2004). Subtle differences in surface roughness length heights have also been shown to impact the downwind distance where air concentration threshold limits are exceeded by several hundred meters (Faulkner et al. 2008). 
Accurate representation of surface roughness and displacement heights is relevant to the mission of the Department of Homeland Security (DHS) Interagency Modeling and Atmospheric Assessment Center (IMAAC). The IMAAC provides a "single point for the coordination and dissemination of Federal dispersion modeling and hazard prediction products that represent the Federal position" during an actual or potential incident (National Response Framework). The Department of Energy's (DOE) National Atmospheric Release Advisory Center (NARAC) at Lawrence Livermore National Laboratory (LLNL) has served as the operations hub of the IMAAC from 2004 to 2012 and is the DOE's plume modeling center for radiological/nuclear releases. NARAC/IMAAC provides plume modeling analyses of hazardous airborne material in real-time to federal, state, and local agencies involved in the response to aid in protecting the public and the environment. NARAC/IMAAC plume plots are used by decision makers and emergency responders to inform decisions on evacuation/shelter-in-place, relocation, public and worker protection, and sampling or monitoring plans.

This report describes new methodologies developed by Goddard Space Flight Center (GSFC) and Stennis Space Center (SSC) scientists for estimating surface roughness and displacement heights from NASA satellite data. The report also summarizes results from an evaluation study that investigates the impact on predicted plume concentrations of integrating NASA surface data into the NARAC/IMAAC modeling system.

\subsection{Project Objectives and Approach}

The goal of this project is to develop algorithms to derive accurate surface roughness and displacement values from NASA satellite data for both urban and vegetation environments and to evaluate the potential benefit of improved surface data characterization on atmospheric transport and dispersion modeling results. The approach used in this project consists of the following steps:

(1) Extension of recently developed and published GSFC/SSC methodologies to generate urban and non-urban surface roughness and displacement height fields covering the continental United States by utilizing NASA Moderate Resolution Imaging Spectroradiometer (MODIS), Landsat, and Shuttle Radar Topography Mission (SRTM) satellite data

(2) Generation of combined urban and non-urban surface characteristics data fields for NARAC/IMAAC dispersion sensitivity simulations over a research domain centered over Oklahoma City

(3) Development of a capability to ingest GSFC/SSC provided surface roughness and displacement height fields into the NARAC/IMAAC modeling system

(4) Investigation of the sensitivity of atmospheric transport and dispersion predictions to incorporating GSFC/SSC-derived surface roughness fields

(5) Formulation of recommendations on future work to evaluate the benefits of using NASA surface roughness products in dispersion modeling decision support tools 
NASA partners with other agencies through Research Opportunities in Space and Earth Science (ROSES) funding in order to extend NASA Earth science research results and data sets to improve Decision Support Tools (DSTs) for national issues such as disaster management. A preliminary scoping assessment made before the start of this project found satellite derived aerodynamic surface roughness provides the best near-term opportunity for incorporation of additional datasets from NASA Earth science measurements into the NARAC/IMAAC DST (Blonski et al. 2007).

Methods developed by GSFC and SSC scientists to estimate surface roughness and displacement height in both urban and non-urban (vegetated) environments are used to create an Integrated System Solution (ISS) for improved Atmospheric Transport and Diffusion (ATD) modeling of atmospheric hazards. This project supports the NARAC/IMAAC mission by investigating the potential of new scientific advances to improve capabilities to provide realtime predictions and analyses of the impacts of hazardous atmospheric biological, chemical, and radiological / nuclear releases to federal, state, and local decision makers. NARAC/IMAAC uses a DST software system for emergency response applications (https://naracweb.llnl.gov), which employs a suite of both meteorological and ATD models.

To study the impact of NASA satellite derived surface data on dispersion modeling results, NASA satellite-derived grid-specific surface roughness and displacement height fields are generated over an Oklahoma City research domain and ingested into the NARAC/IMAAC modeling system. To ensure the data ingestion process is accurate, the surface characteristic fields are verified by comparing grid-cell values with the original data and by examination of NARAC/IMAAC internally-generated plots of surface data fields over the research domain against images produced independently at GSFC/SSC. Grid-specific data fields created during the data ingestion phase then are used to conduct the dispersion model sensitivity evaluation.

We conduct 9 dispersion case studies that correspond to tracer releases made in the central business district of Oklahoma City during the Joint Urban 2003 (JU2003) field experiment. Each of the 9 dispersion cases includes both a CONTROL run (using NARAC/IMAAC default lookup table generated rural surface data parameter values and urban characteristics derived from building-height data) and a NASADATA run (which uses NASA satellite derived surface roughness and displacement height fields). Predicted air concentrations from the dispersion test cases are compared with JU2003 observed average air concentrations to quantify the relative prediction skill of the CONTROL and NASADATA dispersion runs. Simulated peak-air concentrations from the CONTROL and NASADATA runs are also investigated, since peak concentrations are critical to determining the health effects associated with many atmospheric chemical releases. A third set of HYBRID dispersion runs are made for the dispersion test cases consisting of NARAC/IMAAC surface data in urban areas and NASA satellite derived surface data in the rural regions. The HYBRID simulations are used to evaluate the impact of GSFC/SSC surface data on rural air concentrations well away from the release location in the urban center of Oklahoma City. 
Although the current evaluation study is limited to one location, the results are representative of other urban regions, since the Oklahoma City business district is typical of building heights and densities observed in many mid-sized cities in the United States. The NARAC/IMAAC models used in this study are at the high-end of federal emergency response dispersion modeling systems, but results from the data evaluation study are expected to provide insight into the surface data sensitivity of other dispersion modeling systems that can utilize this data.

\subsection{Report Overview}

Evaluating the potential value of using NASA surface data for dispersion modeling applications requires multiple considerations. A summary description of the methodologies developed by NASA's GSFC and SSC to estimate urban and rural surface data is provided in Section 2 of this report. The integration of GSFC/SSC surface data into the NARAC/IMAAC dispersion modeling system is discussed in Section 3 and a brief description of the NARAC/IMAAC models used in this study is presented in Section 4. In Section 5, analysis of the impacts of using NASA surface data on wind modeling and dispersion predictions is covered in detail, with conclusions summarized in Section 6. Section 7 makes recommendations on potential future work to further investigate the potential benefits to atmospheric transport and dispersion modeling from the use of surface characteristics derived from NASA satellite data. 


\section{GSFC/SSC Surface Characteristic Data}

Most atmospheric models assign surface roughness and displacement values for each grid cell in the modeling domain from a look-up table based on the dominant land-cover type in that cell. NASA satellite data provides potential advantages in accuracy when calculating surface characteristics values. Methods to estimate surface data characteristics from satellite measurements were developed by NASA collaborators at Goddard Space Flight Center (GSFC) and Stennis Space Center (SSC) for this project. Specifically, project members at GSFC developed the methodology to calculate rural surface data while project members at SSC focused on developing urban surface data algorithms. In order to provide a continuous surface roughness field for the research domain used within the NARAC/IMAAC atmospheric and transport models, SSC-generated urban roughness pixels were merged with the GSFC derived vegetation roughness fields to create a single combined urban and rural surface characteristic data set. The following sections describe the methodologies developed by GSFC/SSC to generate urban and rural surface characteristics from satellite data.

\subsection{Rural Surface Data}

Roughness length and displacement height fields for all non-urban and non-water regions were generated on a pixel by pixel basis, providing a unique roughness value for each model grid cell within the Oklahoma City research domain. The satellite-based roughness fields were derived as previously described in Jasinski et al. (2005) and Borak et al. (2005) with two additional modifications. First, the original drag parameters in the formulation were updated based on the latest field data obtained from a scientific literature review, yielding new theoretical plots of displacement height and roughness length versus canopy area index. Typical examples for evergreen needle leaf forest and grassland are shown in Figure 2. Second, a procedure for estimating missing Moderate Resolution Imaging Spectroradiometer (MODIS) leaf area index (LAI) data based on spatial and temporal interpolation was developed (Borak and Jasinski 2009). MODIS is a specialized instrument located on the Terra and Aqua satellites that is capable of making high-resolution measurements of land-surface vegetation (Borak et al. 2005). However, an interpolation capability was found to be necessary since in the course of the analysis it was learned that approximately 10 to 20 percent of the MODIS LAI pixels were flagged as poor due to cloud cover. The new interpolation scheme generates continuous roughness fields without missing values. A typical example of a "complete" LAI field with no missing data is shown in Figure 3 for the MODIS 3-10 December 2006 LAI compositing period.

Once a complete time series of LAI was completed, the roughness data products at 1-km horizontal resolution were generated for each MODIS 8-day compositing period over the DOE's Atmospheric Radiation Measurement (ARM) - Cloud and Radiation Testbed (CART) region that includes the Oklahoma City study domain. Each data product consisted of the following three fields: the Canopy Area Index $(\Lambda)$, the vegetation roughness length for momentum $\left(\mathrm{z}_{0}\right)$ and the zero plane displacement height $\left(\mathrm{d}_{0}\right)$. The GSFC methodology yielded a unique roughness value for each $1-\mathrm{km}$ grid cell in the research domain. 

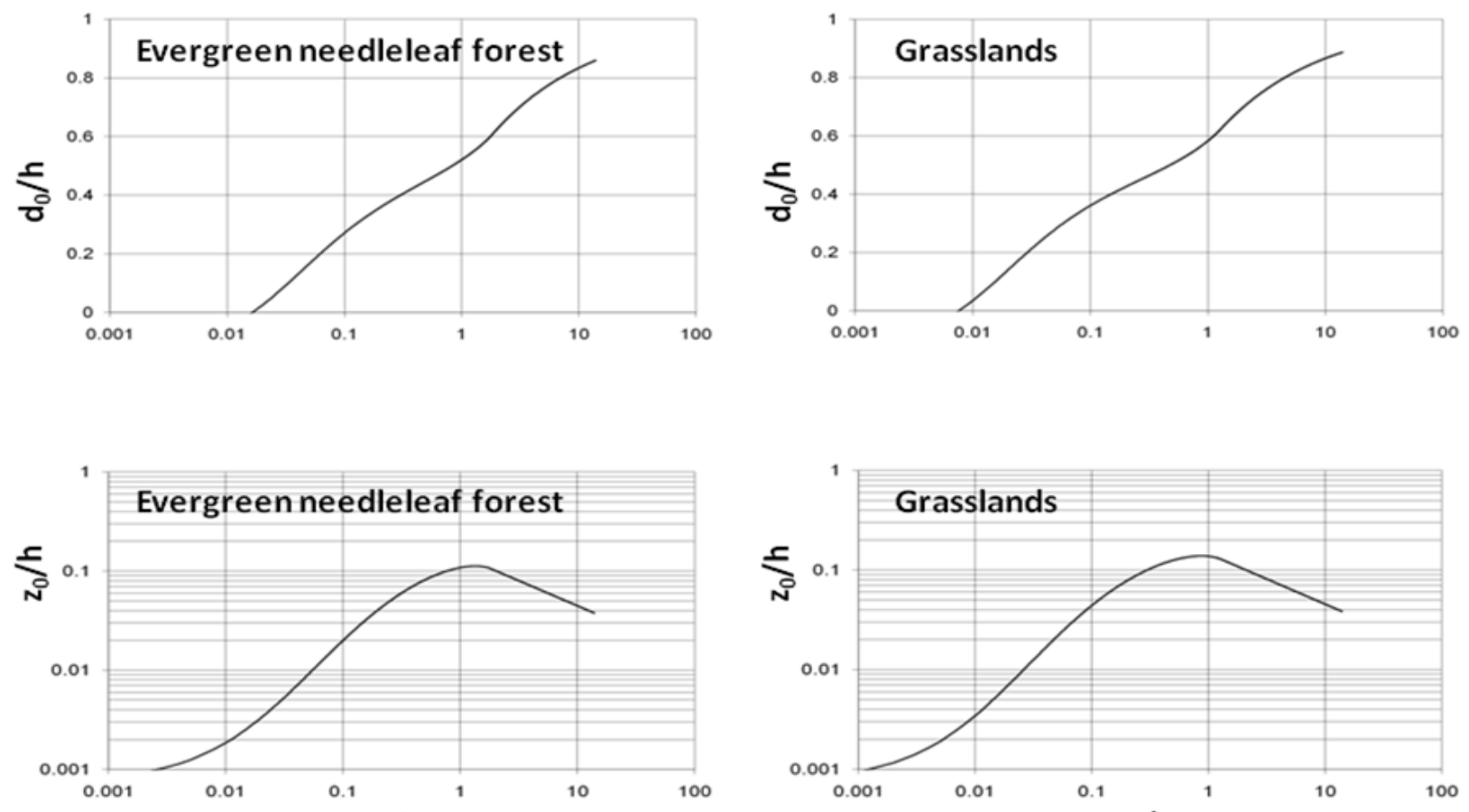

$\Lambda$

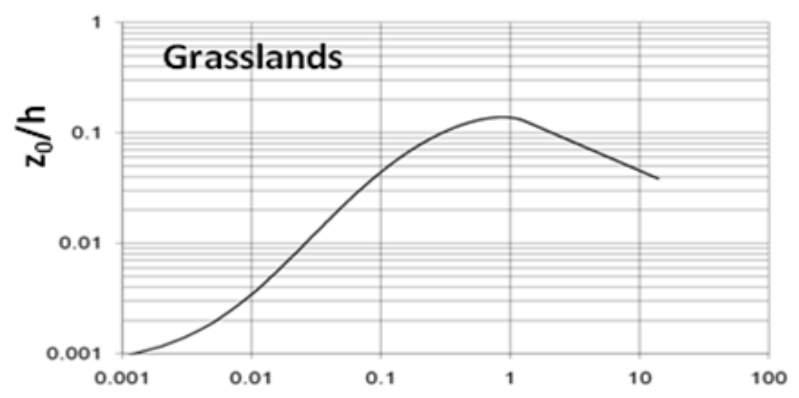

$\Lambda$

Figure 2. Examples of theoretical plots of $d_{0} / h$ and $z_{0} / h$ versus canopy area index, $\Lambda$, for evergreen needleleaf forest (left side of page) and grassland (right side of page) land cover types. Similar plots have been developed for all the principal International Geosphere-Biosphere Programme land classes.

Maps of $\Lambda, z_{0}$ and $d_{0}$ also were created for the continental United States (CONUS) for each compositing period over the complete MODIS period of record (2001 to 2011) to exercise the developed satellite data methodology beyond the Oklahoma City research domain. Examples of maps for $\Lambda, z_{0}$ and $d_{0}$ for both the CONUS and research domain are shown in Figures 4 - 6 for the compositing period June 2-9, 2002.

To ensure the accuracy of the developed surface roughness estimation algorithms, an evaluation of the vegetation roughness fields was conducted. Coefficients in the MODIS roughness procedure were validated based on moment analysis using available field data associated with various land cover types. Additional comparisons were made against local roughness data sets, such as that available from the International H2O Project (IHOP) field experiment (http://www.nssl.noaa.gov/observations/projects/ihop.html). 
(c)

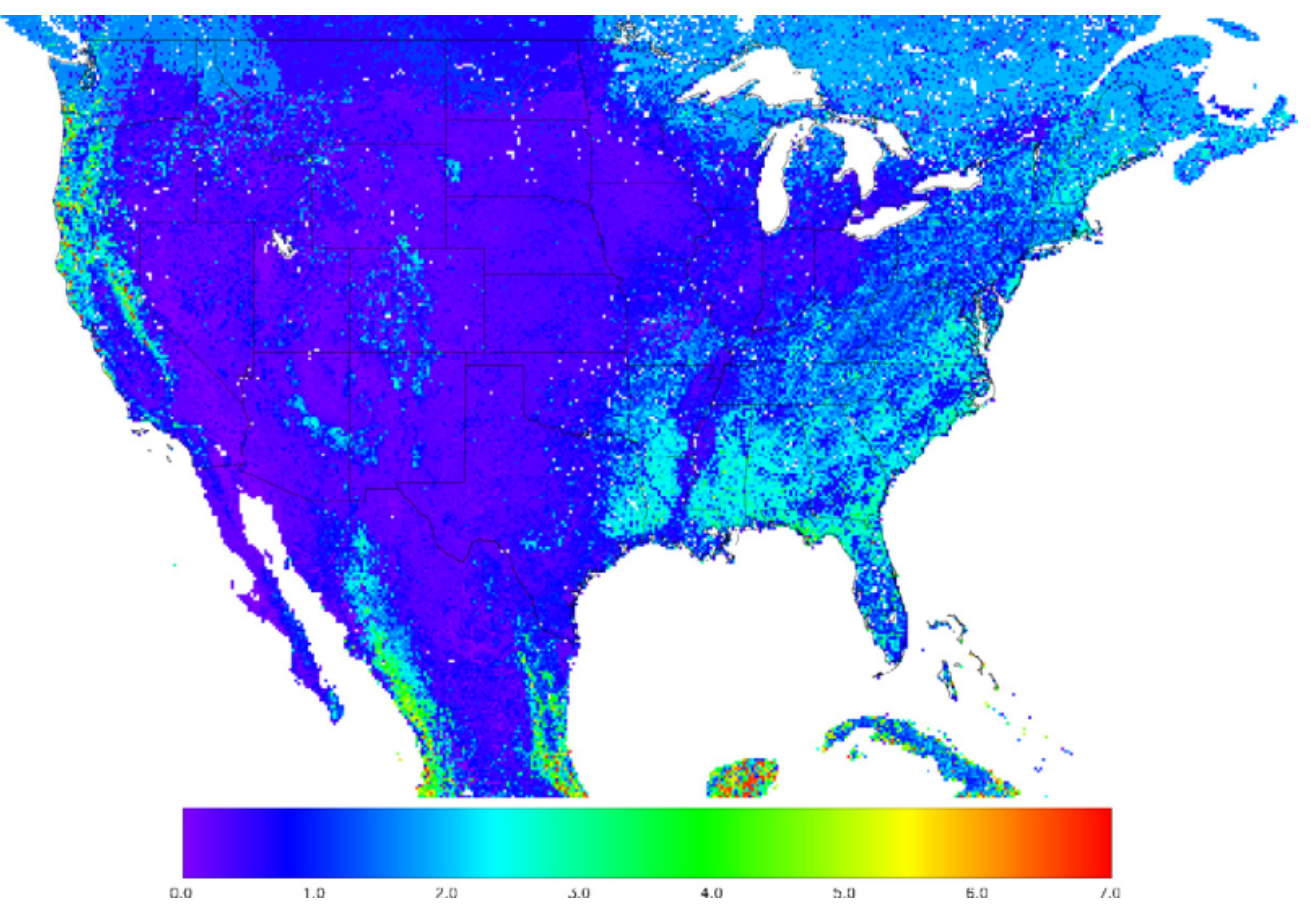

Figure 3. Example of interpolated MODIS LAI field for December 3-10, 2006. The original field included approximately $15 \%$ missing or poor data due to the presence of clouds. The new interpolated field contains no missing data.

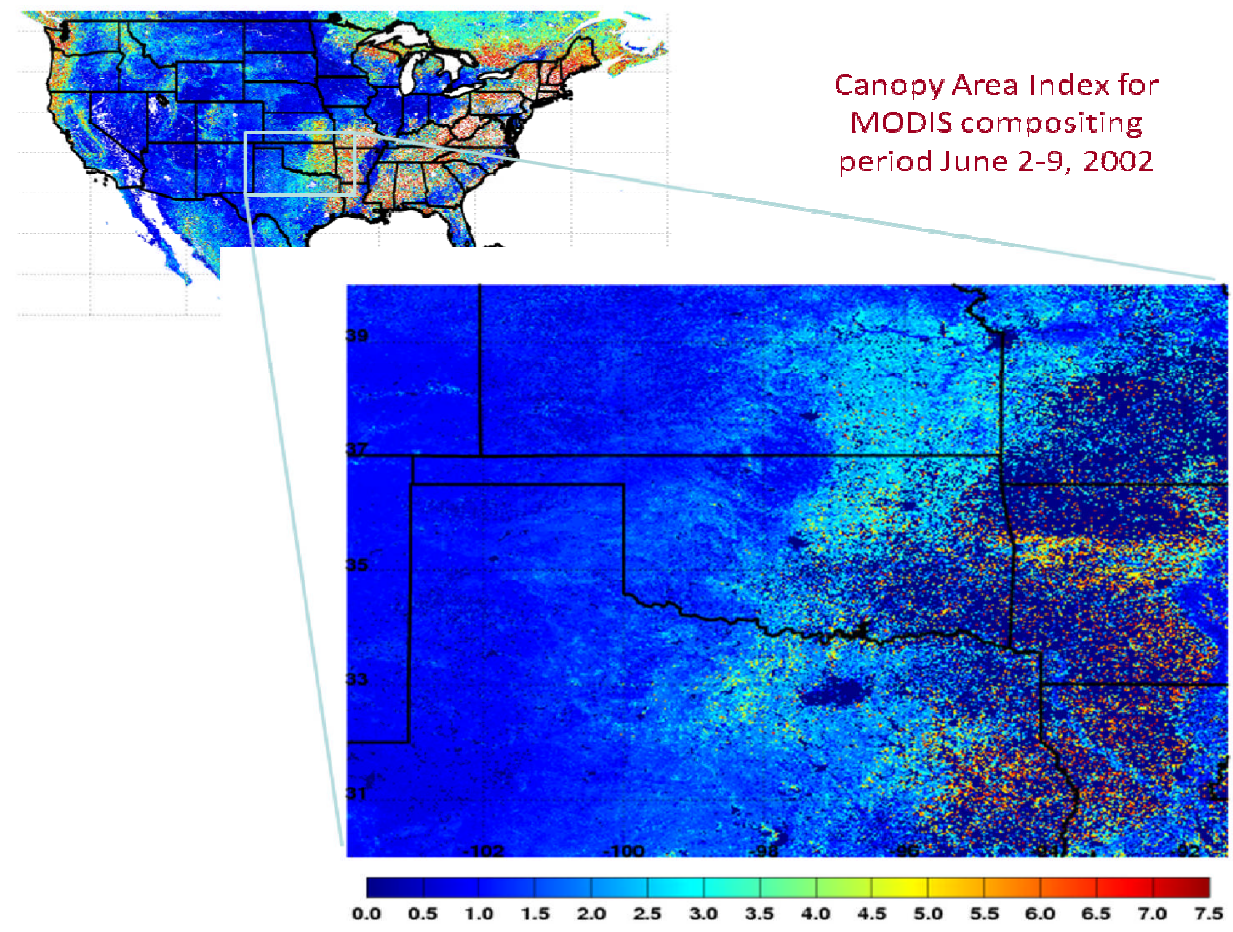

Figure 4. Canopy Area Index for the continental US for the period June 2-9, 2002, including an expanded view covering the ARM-CART region that includes the Oklahoma City research domain. 


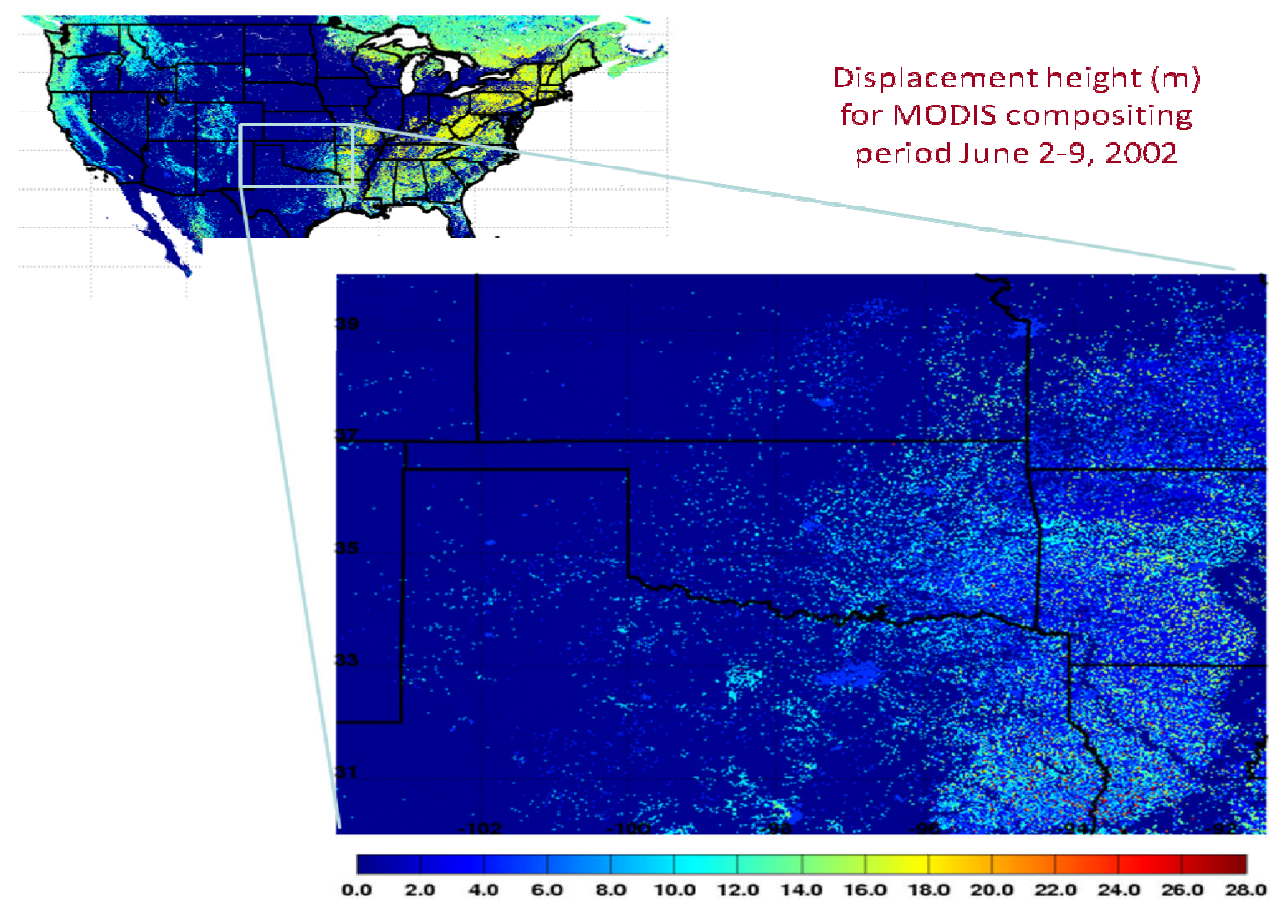

Figure 5. Zero-plane displacement height (m) for MODIS compositing period June 2-9, 2002, including an expanded view covering the ARM-CART region that includes the Oklahoma City research domain.

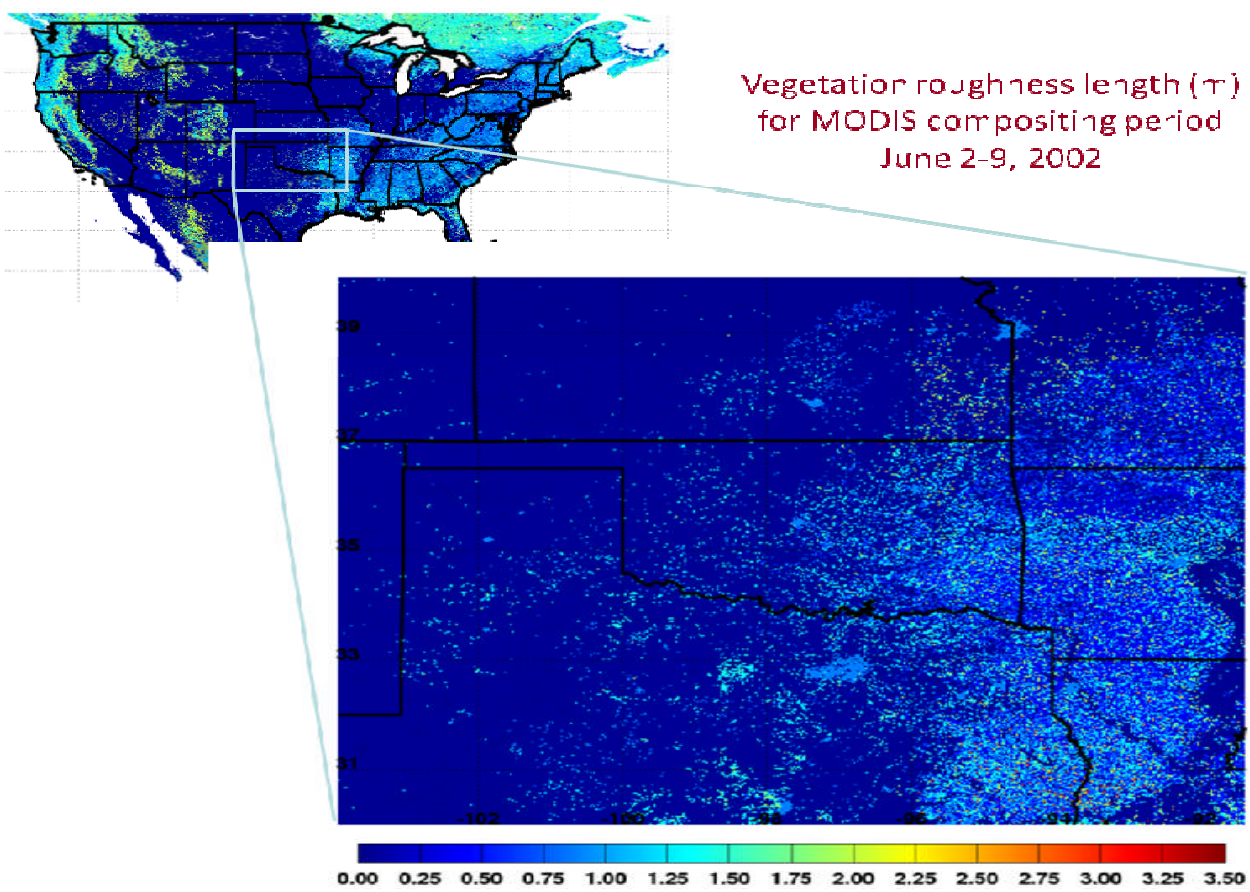

Figure 6. Vegetation momentum roughness length $(\mathrm{m})$ for MODIS compositing period June 2-9, 2002, including an expanded view covering the Oklahoma City research domain. 


\subsection{Urban Surface Data}

SSC created an aerodynamic surface roughness map with 30-m spatial resolution for the Oklahoma City study area based on the land-use classification of the National Land Cover Database (NLCD 2001) that was derived from Landsat data (NASA 2003), supplemented with additional information provided by surface elevation data from the Shuttle Radar Topography Mission (SRTM). The coverage of the high-resolution surface roughness estimates also was extended during the duration of this project to the continental United States (CONUS).

A modified urban look-up table approach was devised that assigned surface roughness length values to each grid cell as a function of NLCD 2001 urban land use category, vegetation canopy coverage, and building height distribution. Table 1 shows the revised mapping derived from a review of data collected by multiple research groups over a number of years (Davenport et al. 2000). To account for the aerodynamic effects of trees present in residential urban areas, open space and low intensity developed areas with NLCD 2001 tree canopy coverage greater than $20 \%$ were assigned the surface roughness of a mixed forest.

Table 1. SSC revised mapping between surface roughness length and NLCD 2001 classes.

\begin{tabular}{|c|c|c|c|}
\hline \multicolumn{2}{|c|}{ NLCD 2001 Class } & Surface Roughness Length & Additional Conditions \\
\hline Code & Name & $(\mathbf{m})$ & \\
\hline 21 & Developed, Open Space & 0.03 & Tree Canopy $\leq 20 \%$ \\
\cline { 3 - 4 } & & 1.0 & Tree Canopy $>20 \%$ \\
\hline \multirow{2}{*}{22} & Developed, Low Intensity & 0.25 & Tree Canopy $\leq 20 \%$ \\
\cline { 3 - 4 } & & 1.0 & Tree Canopy $>20 \%$ \\
\hline 23 & Developed, Medium Intensity & 0.5 & SRTM - NED $\leq 10 \mathrm{~m}$ \\
\cline { 3 - 4 } & & 6.0 & SRTM - NED $>10 \mathrm{~m}$ \\
\hline \multirow{2}{*}{24} & Developed, High Intensity & 1.0 & SRTM - NED $\leq 10 \mathrm{~m}$ \\
\cline { 3 - 4 } & & 6.0 & SRTM - NED $>10 \mathrm{~m}$ \\
\hline
\end{tabular}

In atmospheric modeling, urban grid cells are often assigned identical roughness length values without accounting for the heterogeneity of urban landscapes. Thus, an additional objective of this project was to take into account the spatial variability of urban roughness fields by using auxiliary digital elevation data extracted from satellite radar measurements or stereoscopic imaging. Tall building areas in urban centers (which typically contain a mixture of low-rise and high-rise buildings) were identified based on the difference between the SRTM elevation measurements and the bare ground elevation data from the National Elevation Dataset (NED) produced by the USGS. The medium and high intensity developed areas with an SRTM-NED difference larger than $10 \mathrm{~m}$ were assigned a "chaotic" surface roughness type. While the Davenport 2000 review paper cited above specifies only that the surface roughness value should be greater than $2 \mathrm{~m}$ for tall building areas, a roughness length of $6 \mathrm{~m}$ was selected after reviewing recent publications on experimental studies of wind profiles in relativelyhomogenous urban landscapes (Cao et al. 2009; Al-Jiboori and Fei 2005; Chang and Huynh 
2007). Since the selected roughness length for the high-resolution, 30-m grid significantly exceeds values typically used in similar work, parametric studies were conducted to determine the sensitivity of the aggregated (to $1-\mathrm{km}$ ), mesoscale roughness length to the choice of this value for the "chaotic" urban class.

The 30-m urban surface roughness map was aggregated to the 1-km grid cell size of the GSFC MODIS-LAI seasonal vegetation surface roughness map (Figure 7). This allowed SSC-derived values for urban pixels to be substituted for the GSFC-derived surface roughness data, which does not include urban roughness values. Several methods were investigated for fusing the higher and lower-resolution surface roughness estimates, including the geometric/logarithmic mean and the arithmetic mean. A blending height method based on Bou-Zeid et al. (2007) was ultimately selected for this purpose. In this approach, the blending height parameter was determined for each grid cell based on formulae derived from large-eddy aerodynamic simulations and on spatial statistics (variograms) of high-resolution surface roughness within the grid cell. Although this method is more computationally intensive than the other methods, it provides a physics-based approach for determining effective surface roughness over the heterogeneous urban terrain. For urban areas, this method predicts that the roughness is not uniform and increases significantly in regions containing very tall buildings, even after averaging to the lower resolution grids used in mesoscale simulations. The blended urban roughness fields were evaluated based on morphometric analysis of very high-resolution elevation data available for urban centers from Light Detection and Ranging (LIDAR) measurements.

Using the same, modified blending height method, the 30-m roughness map created for the CONUS area was also aggregated to the 500-m sinusoidal grid of the most recent MODIS Collection 5 LULC product (Figure 8). This large computational effort has enabled studies of the heterogeneity of roughness length for each IGBP (International Geosphere-Biosphere Programme) class identified in the MODIS LULC product. 

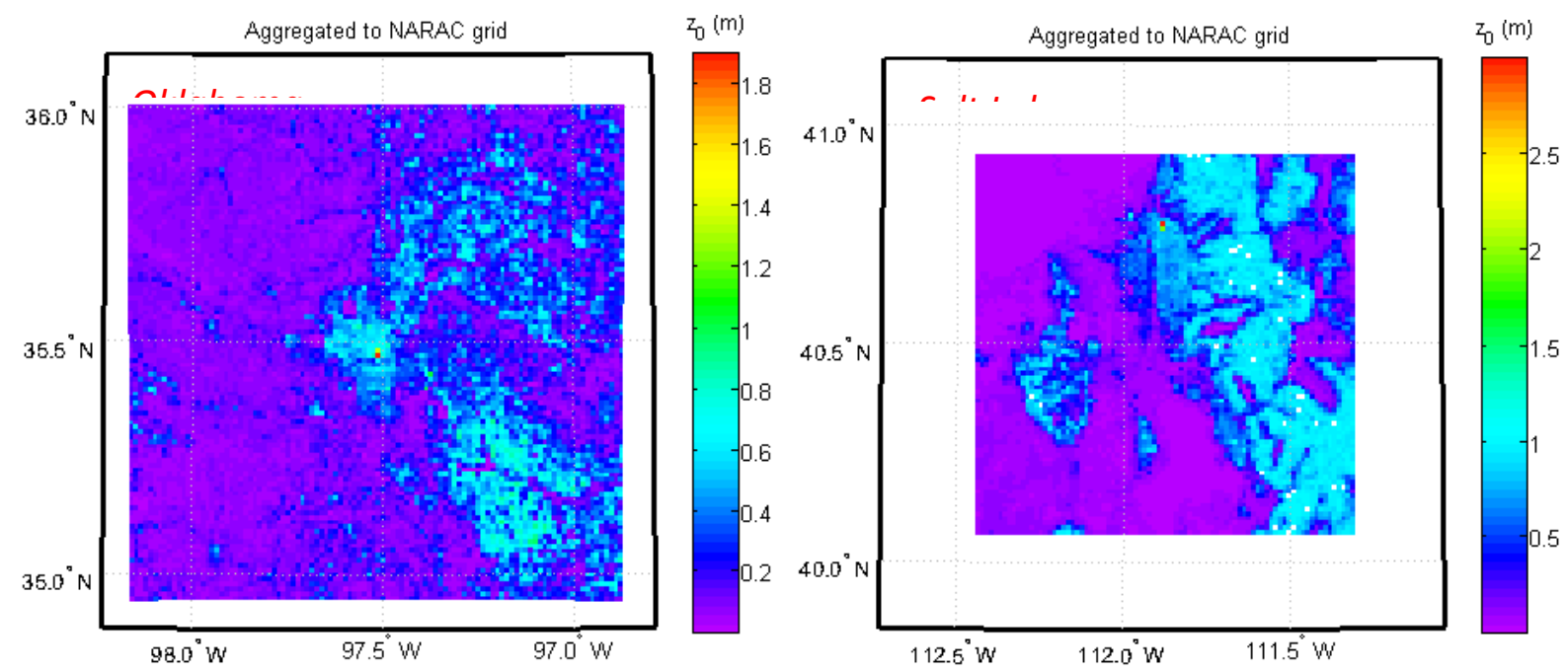

Figure 7. Maps of aerodynamic surface roughness lengths derived from blended $30 \mathrm{~m}$ Landsat-LULC and SRTM-DEM data and aggregated to a 1-km grid for Oklahoma City (left) and Salt Lake City (right). On each image, the one red pixel indicates a tall building area with high urban roughness.

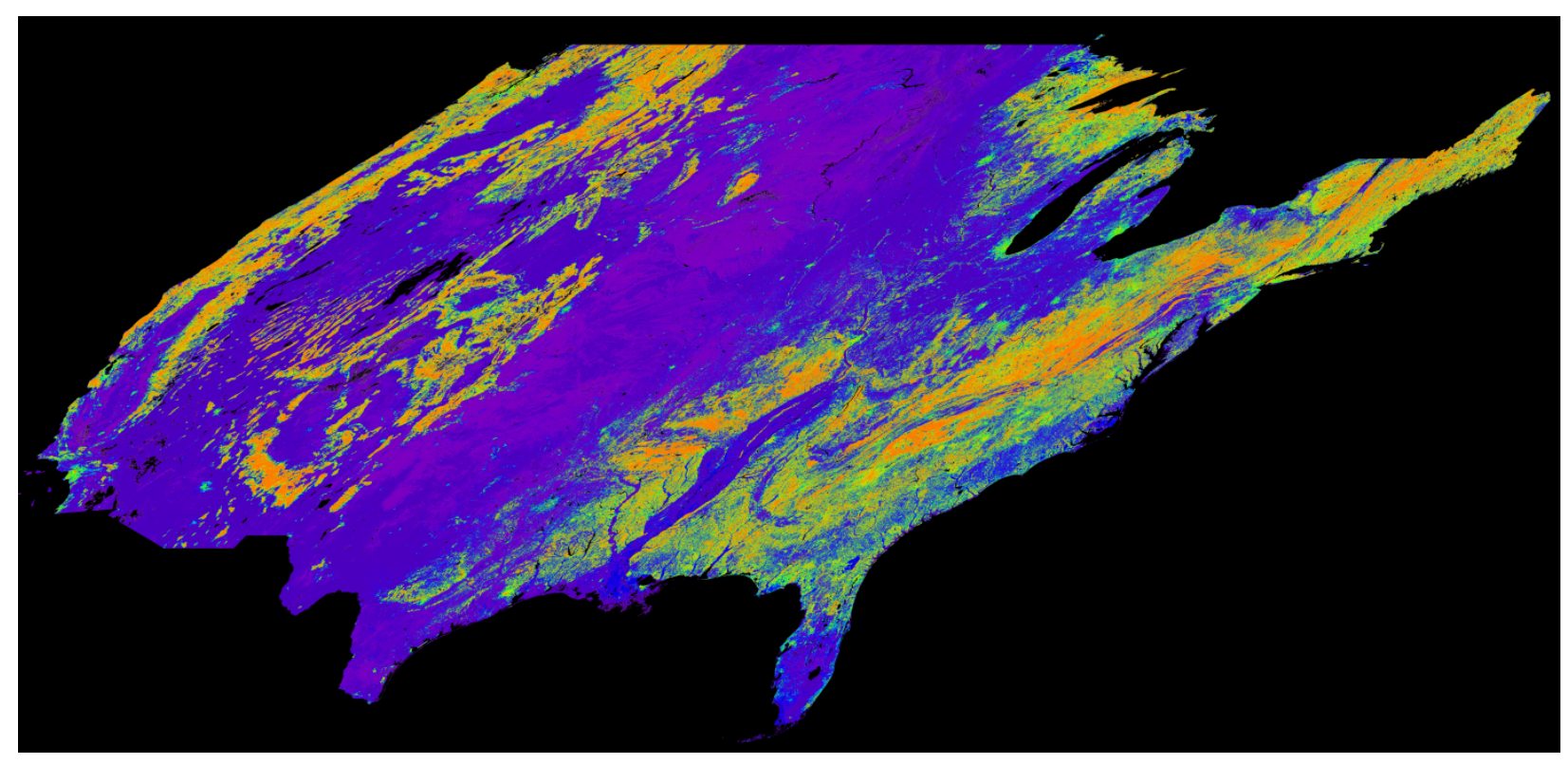

Figure 8. Map of aerodynamic surface roughness length derived from 30-m Landsat land-use / land-cover and SRTM-DEM data aggregated to the 500-m MODIS sinusoidal grid for the CONUS area. 


\section{Integration of Surface Data}

The following section provides a summary of the NARAC geospatial data processing (Geodata) subsystem and describes how the NASA data derived surface roughness and displacement height fields were integrated for use in the dispersion evaluation study. The Geodata subsystem is populated with a variety of data sets that reflect the current requirements of NARAC/IMAAC operations along with the needs of model research and development efforts. The categories of geospatial data that are relevant to the work performed during this project are Land Characteristics data and Building Geometry data.

The Geodata subsystem supports a continuous range of model sophistication and resolution because NARAC/IMAAC responds to national and international events on multiple scales (local to regional to global). It provides a range of metadata management, input, output, transformation, resampling and orchestration capabilities that are used to provide geographic data in a form that is convenient for use in the atmospheric, source and effects models as well as the analysis capabilities that are used in the NARAC/IMAAC system.

\subsection{NARAC Land Characteristics Data}

NARAC/IMAAC uses the most recent National Land Cover Database (NLCD) data (Fry et al. 2011) within the United States and the Oak Ridge National Laboratory (ORNL) LandScan Global Database for areas outside the U.S. NLCD 2006 data are available at 30-m resolution and a list of the land use categories found in the data set is provided in Table A-1 in the Appendix.) Global LandScan data are available at approximately 1-km resolution.

\subsection{NARAC Building Geometry Data}

The National Geospatial-Intelligence Agency (NGA) and Science Applications International Corporation (SAIC) provide NARAC with shapefile data of building footprints and heights, which approximate complex buildings by multiple contiguous footprints with differing heights. These data are currently available for most of the major cities in the U.S. with estimated positional accuracy of 3-4 meters. The NARAC Geodata system has processed this data to compute and average various geometric attributes (e.g., building area and area-averaged building heights) on a convenient $250-\mathrm{m}$ resolution grid. This gridded data is used for intermediate fidelity modeling applications such as a regional scale urban canopy parameterization.

\subsection{GSFC/SSC Data Integration}

GSFC/SSC-provided surface roughness and displacement height grid fields and an urban/rural land use mask for the Oklahoma City domain of interest. Multiple binary data files in an agreed upon format were used to describe the surface characteristics over an 8-day period during the summer of 2003. The data were specified on the UTM projection appropriate for Oklahoma City (central longitude of $-99 /$ band 14). Coordinate information specifying the grid origin, grid step and grid dimensions was provided in a separate text file. These data were used to register the 
GFSC/SSC surface data within the NARAC Geodata subsystem. This registration process adds metadata describing the data (including temporal information), which is subsequently used by the Geodata system to select the appropriate data to be used in a given simulation.

A target grid was defined that exactly matched the native-grid of the GFSC/SSC data so that the Geodata system output could echo the original data exactly. Values in the GFSC/SSC data files were directly compared to the values in NetCDF data files generated by the Geodata system as a validation check. Data-grid visualizations using the same color map were also used for additional cross-checks to ensure that the data had been transferred and integrated correctly.

\subsection{NARAC Land Characteristic Data Processing}

Geographic data that describes the land surface, such as $z_{0}$ and $d$, are packaged with land characteristics data in a NARAC Geodata system NetCDF file. In the absence of better data sources, a look-up table is used to assign a value of $\mathrm{z}_{\mathrm{o}}$ and $\mathrm{d}_{0}$ for each land characteristics type in the USGS NLCD classification system. The default values for surface roughness length, displacement height, and building height (used when observed building data are unavailable) as a function of land use category are shown in Table A.1. Default surface characteristic values can subsequently be overridden by higher quality data for each grid cell where such data exists. This process ensures that there is no missing data in the file that could cause spurious model behavior.

The NGA/SAIC building data currently provides a higher quality data source for $\mathrm{z}_{\mathrm{o}}$ and $\mathrm{d}_{0}$ in urban areas. For grid cells where these data are available, $z_{o}$ is set to $10 \%$ of the area-averaged building height and $\mathrm{d}_{0}$ is set to $50 \%$ of the area-averaged building height as described in Burien (2005). These data were used in the CONTROL runs of the dispersion model evaluation study discussed in Sections 5 and 6.

The GSFC/SSC $z_{o}$ and $\mathrm{d}_{0}$ data provide an alternate source of potentially higher quality data than the default NARAC table-driven values from the land characteristics data. For grid cells where these data exists, values from earlier processing are replaced by GSFC/SSC data values in the NASADATA runs of the model evaluation study. Additional controls added to the land characteristics processing software during this project were used to test different methods for combining the three data sources, including using the NASA-provided urban/rural mask to control where a given data set was used. 


\section{NARAC Modeling System}

This project uses two of the NARAC/IMAAC operational models. The Atmospheric Data Assimilation and Parameterization Techniques (ADAPT) model generates meteorological fields and atmospheric transport and dispersion is simulated by the Lagrangian Operational Dispersion Integrator (LODI) model. Both models were developed at Lawrence Livermore National Laboratory (LLNL) for NARAC/IMAAC operational emergency response dispersion predictions (Nasstrom et al. 2007; Sugiyama et al. 2010). ADAPT/LODI are coupled to databases that provide topography, geographical data, chemical-biological-nuclear agent properties, realtime meteorological observational data, and global and mesoscale forecast model predictions. Additional software provides source term information and post-processes LODI output to estimate potential health impacts and contamination levels.

\subsection{ADAPT}

ADAPT (Sugiyama and Chan 1998) assimilates data from meteorological observations (e.g., surface stations, radiosondes and profilers) and/or weather forecast models, as well as landsurface characteristic data. ADAPT constructs meteorological fields (mean winds, pressure, precipitation, temperature, turbulence quantities, etc.) based on a variety of interpolation methods and atmospheric parameterizations (Chan and Sugiyama 1997; Sugiyama and Chan 1998). Non-divergent wind fields are produced using an adjustment procedure based on the variational principle and a finite-element discretisation. The solution is obtained via conjugate gradient solvers that include a stabilization matrix to improve computational efficiency.

ADAPT estimates turbulence quantities required by the dispersion model, LODI, using similarity theory scaling relationships. The turbulent diffusivities, $K_{x}, K_{y}$ and $K_{z}$, are calculated as a function of height and horizontal location using scaling relationships as described by Nasstrom et al. (2000). The methods summarized by van Ulden and Holtslag (1985) can be used to estimate surface heat and momentum fluxes and turbulence scaling parameters (e.g., friction velocity, $u_{*}$, Obukhov length, $L$, convective velocity scale, $w_{*}$, and boundary layer depth, $\mathrm{h}_{\mathrm{pbl}}$ ) from near-surface meteorological observations and land-use data.

ADAPT has two methods for constructing vertical wind profiles in the surface layer. The first method uses an exponential power function to estimate the surface layer wind profile as given by:

$$
\mathrm{u}\left(\mathrm{z}_{2}\right)=\mathrm{u}\left(\mathrm{z}_{1}\right)\left(\frac{\mathrm{z}_{2}}{\mathrm{z}_{1}}\right)^{\gamma}
$$

where $\mathrm{u}$ is the wind speed as a function of height (z) and $\gamma$ is a power law exponent, which is dependent on the height above ground, atmospheric stability, and the surface roughness length. The second surface layer wind method utilizes the traditional form of the logarithmic wind speed profile (Tennekes 1973; Stull 1993). The log wind speed profile is an experimentally derived approximation of the surface layer wind profile given by: 


$$
\mathrm{u}(\mathrm{z})=\frac{\mathrm{u}_{*}}{\mathrm{k}} \ln \left(\frac{\mathrm{z}}{\mathrm{z}_{\mathrm{o}}}\right)
$$

where $\mathrm{u}$ is the wind speed as a function of height ( $\mathrm{z})$, $\mathrm{z}_{\mathrm{o}}$ is the roughness length, $\mathrm{k}$ is the von Karmon constant, and $u_{*}$ is the friction velocity. Standard correction terms can be used to account for stability (not included in eqn. 2 for simplicity). The choice of ADAPT's surface layer wind method has minimal impact on results for most scenarios (Sugiyama and Chan 1998). The logarithmic wind profile method (eqn. 2) was used for the ADAPT modeling results presented in this report.

When not explicitly defined via a namelist parameter, the friction velocity $\left(u_{*}\right)$ is internally calculated in ADAPT by:

$$
\mathrm{u}_{*}=\frac{\mathrm{k}\left(\mathrm{u}^{2}+\mathrm{v}^{2}\right)^{1 / 2}}{\ln \left(\frac{\mathrm{z}-\mathrm{d}_{0}}{\mathrm{z}_{\mathrm{o}}}\right)-\psi(\mathrm{z})+\psi\left(\mathrm{z}_{\mathrm{o}}+\mathrm{d}_{0}\right)}
$$

where $\mathrm{u}$ and $\mathrm{v}$ are the horizontal wind components, $\mathrm{k}$ is the von Karman constant, $\mathrm{zo}$ is the roughness length, $\mathrm{d}_{0}$ is the displacement height, $\mathrm{z}$ is the height above ground level, and $\psi$ is a stability correction term defined by van Ulden and Holtslag (1985).

The vertical eddy diffusivity parameter $\left(\mathrm{K}_{z}\right)$ within the planetary boundary layer is calculated based on similarity theory as:

$$
\mathrm{K}_{z}^{b l}(\mathrm{z})=\frac{\mathrm{ku}_{*}\left(\mathrm{z}-\mathrm{z}_{g}\right)}{\varphi_{h}} e^{-\frac{c\left(\mathrm{z}-\mathrm{z}_{g}\right)}{h_{p b l}}}
$$

where $\mathrm{k}$ is the von Karman constant, $u_{*}$ is the friction velocity, $\mathrm{c}$ is an empirical constant with default value of $4, \mathrm{~h}_{\mathrm{pbl}}$ is the planetary boundary layer height, and $\varphi_{\mathrm{h}}$ is a stability correction term utilizing the Monin-Obukhov length scale.

The horizontal turbulence parameter, $\sigma_{v}$, which describes the variance in the horizontal velocity field, is calculated separately in ADAPT for unstable atmospheric conditions and stable / neutral conditions according to:

unstable

$$
\sigma_{v}^{2}=\mathrm{Au}_{*}^{2}\left(1-\frac{\mathrm{z}-\mathrm{z}_{g}}{\mathrm{~h}_{\mathrm{pbl}}}\right)^{3 / 2}+\mathrm{BW}_{*}^{2}
$$

stable / neutral

$$
\sigma_{v}^{2}=A_{u}^{2}\left(1-\frac{z_{-}-z_{g}}{\mathrm{~h}_{\mathrm{pbl}}}\right)^{3 / 2}
$$

where $u_{*}$ is the friction velocity, $\mathrm{h}_{\mathrm{pb}}$ is the planetary boundary layer height, $w_{*}$ is the convective velocity scale parameter, and A and B are stability dependent coefficients. 


\subsection{ADAPT Urban Canopy Parameterization}

The previously described equations are not valid in urban areas where large buildings impact the mean wind flow and enhance turbulent mixing. ADAPT contains a sophisticated urban canopy module (Delle Monache et al. 2009) that more accurately represent the complex vertical structure of wind and turbulence observed in urban environments. The urban canopy module breaks the lower atmosphere down into the following three layers:

- Urban canopy layer (UCL), which covers the surface up to the average building height in the grid cell (h),

- Roughness sublayer (RSL), from $h$ to $3 h$, and

- Inertial sublayer (ISL), assumed to be $10 \%$ of the planetary boundary layer depth.

Separate equations are used to parameterize the vertical wind profile structure in each of the three urban sublayers. Wind profiles in the UCL, RSL, and ISL are primarily influenced by the average building height, friction velocity, displacement height, roughness length, and stability correction terms based on the Monin-Obukhov length scale.

In the urban canopy, the friction velocity and Monin-Obukhov length are calculated via an iterative procedure (Perry 1992) that is influenced by the surface roughness length. This iterative calculation requires the surface sensible heat flux, which we calculate using a modified form of the AERMET model (Cimorelli et al. 2005) to more accurately represent the ratio of sensible heat flux to net radiation in the energy balance equation for urban regions (Simpson et al. 2007).

Additional sublayer dependent equations are used to calculate horizontal velocity variances and vertical eddy diffusivities within the urban canopy. Enhanced horizontal mixing in the canopy is predominantly accounted for via a modified friction velocity, which includes the impact of the urban roughness length. Increased vertical eddy diffusivity in the urban canopy is incorporated by the use of several length scale parameters that are functions of the surface roughness and displacement height.

The accuracy of ADAPT/LODI calculations are dependent on the representativeness of surface roughness and the displacement height as incorporated into the equations for vertical wind profiles and horizontal and vertical turbulent mixing. Inaccurate estimates of rural and urban surface characteristics will have an impact on the mean transport of atmospheric particulates via the wind speed profile and the horizontal and vertical spread of a plume via the turbulence parameterizations.

\subsection{LODI}

The LODI dispersion model (Leone et al., 2005) is used for regional to global scale atmospheric plume prediction. LODI is a three-dimensional Lagrangian stochastic, Monte Carlo particle dispersion model that uses wind and turbulence fields generated by ADAPT. LODI simulates the processes of mean wind advection, turbulent diffusion, radioactive decay, first-order 
chemical reactions, wet deposition, gravitational settling, dry deposition and buoyant/momentum plume rise. Additional terms are used to calculate the production of radionuclides due to the decay and in growth of a decay chain. LODI solves the advectiondiffusion equation using a Lagrangian stochastic, Monte Carlo method (Ermak and Nasstrom, 2000). Particle displacements due to the mean wind are calculated using the Runge-Kutta method. The displacement of a particle due to turbulent diffusion is based on a skewed, nonGaussian particle position probability density function, necessary for the efficient simulation of diffusion in inhomogeneous turbulence (especially near the ground surface). 


\section{Discussion of Modeling Results}

A data evaluation study was conducted to understand the impact of GSFC/SSC satellite derived surface characteristic data on dispersion modeling. This section discusses the evaluation results based on comparisons against measured air concentrations from the Joint Urban 2003 (JU2003) field experiment (Allwine et al., 2004). The main goal of JU2003 was to better understand the impact of urban environments on wind flow and atmospheric dispersion by collecting meteorological and air concentration data at time and length scales capable of resolving the complex range of scales of motion associated with urban flow patterns (Allwine and Flaherty 2006). Data collected during JU2003 is being used to improve existing dispersion models and to provide valuable insight into complex urban flow patterns for the development of the next generation of fine-scale computational fluid dynamics (CFD) models.

Most of the buildings in OKC are around 15 to $50 \mathrm{~m}$ tall, with a few taller than $75 \mathrm{~m}$, making it representative of many moderate-sized urban centers found in the United States. OKC is also located on flat terrain, which is ideal for an urban dispersion experiment as complex terrain features will not introduce enhanced turbulence and further increase the complexity of evaluation.

\subsection{Evaluation Methodology}

JU2003 was conducted in the central urban region of Oklahoma City, OK (OKC) from 28 June to 31 July, 2003. A series of sulfur hexafluoride 30-minute tracer releases were made from either the OKC Botanical Gardens or the Westin Hotel during each of 10 intensive observation periods (IOPs). The tracers were released from a height of $2 \mathrm{~m}$ above ground. Ground-based air concentration samplers at a height of $3 \mathrm{~m}$ were deployed in the central business district (CBD) of OKC and on receptor arcs at 1,2, and $4 \mathrm{~km}$ distance from the source location as shown in Figure 9. A total of 120 air concentration samplers were used during JU2003, with 55 samplers in the CBD and the remaining 65 in the sampler arcs. Concentration measurements at multiple distances from the source allow the analysis of the impact of GSFC/SSC data on dispersion predictions as a function of distance from the release location. Due to the limited number of tracer releases during JU2003, results from the dispersion case studies may not be statistically significant. However, the results are sufficient to reach conclusions on the sensitivity of dispersion modeling to roughness values in an urban environment.

We simulated 9 dispersion test cases within the central business district of Oklahoma City consisting of CONTROL and NASADATA simulations. All of the dispersion test cases for the data evaluation correspond to JU2003 daytime releases, since the ADAPT urban canopy model has been shown to perform best during convective, unstable atmospheric conditions (Delle Monache et al. 2009). The CONTROL dispersion runs used standard NARAC surface roughness and displacement height values derived from the land-use look-up table and the urban corrections based on the NGA/SAIC building data as described in Section 3, while the NASADATA runs used the new satellite derived surface data. 
In addition to comparing CONTROL and NASADATA dispersion predictions with observed air concentrations, we performed a model to model air concentration analysis that compared CONTROL and NASADATA predicted peak air concentrations to gain insight into the sensitivity of near source concentrations to surface data values. The peak air concentration is an important consideration in evaluating the GSFC/SSC surface data for emergency response modeling because it is critical to determining health effects associated with many hazardous chemical releases.

A third set of HYBRID runs were made that combined NARAC default surface data (derived from NGA/SAIC building height data) for urban land use and NASA derived surface data for rural land use. By comparing predicted concentrations from the CONTROL and HYBRID runs, we investigated the impact of GSFC/SSC surface data on plume centerline concentrations in rural areas downwind of the urban release location.

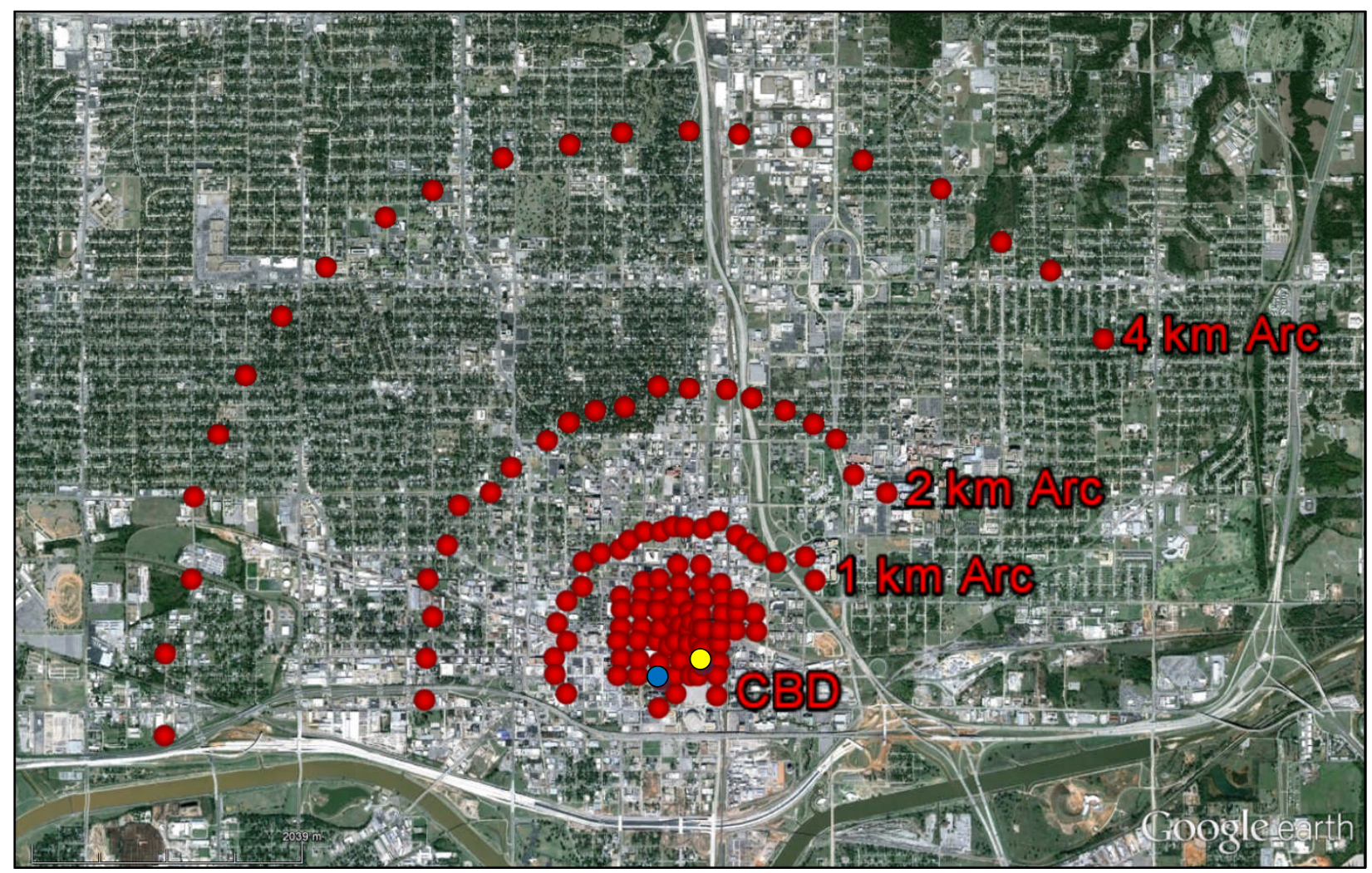

Figure 9. Map showing the location of Joint Urban 2003 air concentration samplers in the Central Business District (CBD) of Oklahoma City and at arcs 1, 2, and $4 \mathrm{~km}$ distance from the atmospheric release location in the CBD. The location of the OKC Botanical Gardens is denoted by the blue circle, while the Westin Hotel is represented by the yellow circle.

We simulated dispersion test cases on 2, 7, and 9 July 2003, which correspond to JU2003 IOP 2, 3 , and 4 respectively. A total of 9 dispersion test cases were included in the evaluation study with 3 trial releases simulated for each IOP. The dominant wind direction during the evaluation study IOP days was from the south to southwest. Wind speeds during IOP 2 were 
between 4.5 and $5.2 \mathrm{~m} / \mathrm{s}$, while winds were higher on IOP 3 and 4 with observed average speeds in the 6.5 to $7.9 \mathrm{~m} / \mathrm{s}$ range. The release time, dominant wind speed and direction, release rate and location for the nine dispersion test cases used in the GSFC/SSC data evaluation study are provided in Table 2.

Table 2. JU2003 IOP number, release time, dominant wind speed and direction, release rate, and release location of the dispersion test cases used in the data evaluation study.

\begin{tabular}{|c|c|c|c|c|c|}
\hline IOP Number & Release Time & $\begin{array}{c}\text { Wind } \\
\text { Speed }(\mathrm{m} / \mathrm{s})\end{array}$ & $\begin{array}{c}\text { Wind Dir. } \\
\text { (degrees) }\end{array}$ & $\begin{array}{c}\text { Release } \\
\text { Rate }(\mathrm{g} / \mathrm{s})\end{array}$ & $\begin{array}{c}\text { Release } \\
\text { Location }\end{array}$ \\
\hline IOP 2 - Trial 1 & 2 July 16:00 - 16:30 UTC & 5.0 & 234 & 5.0 & Westin \\
\hline IOP 2 - Trial 2 & 2 July 18:00 - 18:30 UTC & 4.5 & 200 & 5.0 & Westin \\
\hline IOP 2 - Trial 3 & 2 July 20:00 - 20:30 UTC & 5.2 & 171 & 5.0 & Westin \\
\hline IOP 3 - Trial 1 & 7 July 16:00 - 16:30 UTC & 7.4 & 203 & 5.0 & Bot. Garden \\
\hline IOP 3 - Trial 2 & 7 July 18:00 - 18:30 UTC & 6.5 & 190 & 3.0 & Bot. Garden \\
\hline IOP 3 - Trial 3 & 7 July 20:00 - 20:30 UTC & 7.6 & 195 & 3.0 & Bot. Garden \\
\hline IOP 4 - Trial 1 & 9 July 16:00 - 16:30 UTC & 6.9 & 212 & 3.1 & Bot. Garden \\
\hline IOP 4 - Trial 2 & 9 July 18:00 - 18:30 UTC & 7.9 & 197 & 3.0 & Bot. Garden \\
\hline IOP 4 - Trial 3 & 9 July 20:00 - 20:30 UTC & 7.9 & 199 & 3.0 & Bot. Garden \\
\hline
\end{tabular}

The ADAPT model grid used in this study consists of $90 \times 90$ grid cells with a horizontal grid spacing of $1 \mathrm{~km}$ centered on Oklahoma City and extending to the surrounding rural area. A total of 40 vertical levels are in the ADAPT grid, 10 of which are located in the first $100 \mathrm{~m}$ of the lower atmosphere.

Meteorological variables used by ADAPT to construct wind and turbulence profiles include wind speed and direction, while surface temperature, pressure, multi-level lapse rate from soundings, and cloud cover fraction are used to calculate the hourly surface sensible heat flux values used by the ADAPT urban canopy model. The atmospheric data for the dispersion test cases are provided by 5 surface and one upper air meteorological stations that surround OKC, which represent standard data available in real-time. Weather observations taken in the urban region of OKC during JU2003 are not used, since the urban canopy module is designed to work with quality controlled observations taken at non-urban sites that typically represent the only source of weather data available during an emergency response situation.

The surface weather stations range in distance between 11 and $57 \mathrm{~km}$ from the OKC business district where the JU2003 tracer releases occurred. The weather stations used are Wiley Post Airport (call sign KPWA), Chickasha (KCHK), Will Rogers World Airport (KOKC), Tinker Air Force Base (KTIK), and Guthrie-Edmund Regional Airport (KGOK). Locations of the weather stations used in the evaluation study in relation to the central business district of OKC are shown in Figure 10. Upper air meteorological data for the ADAPT model is provided by 
radiosonde soundings conducted at the University of Oklahoma Westheimer Airport (KOUN) located in Norman, OK, which is located approximately $30 \mathrm{~km}$ to the south of OKC.

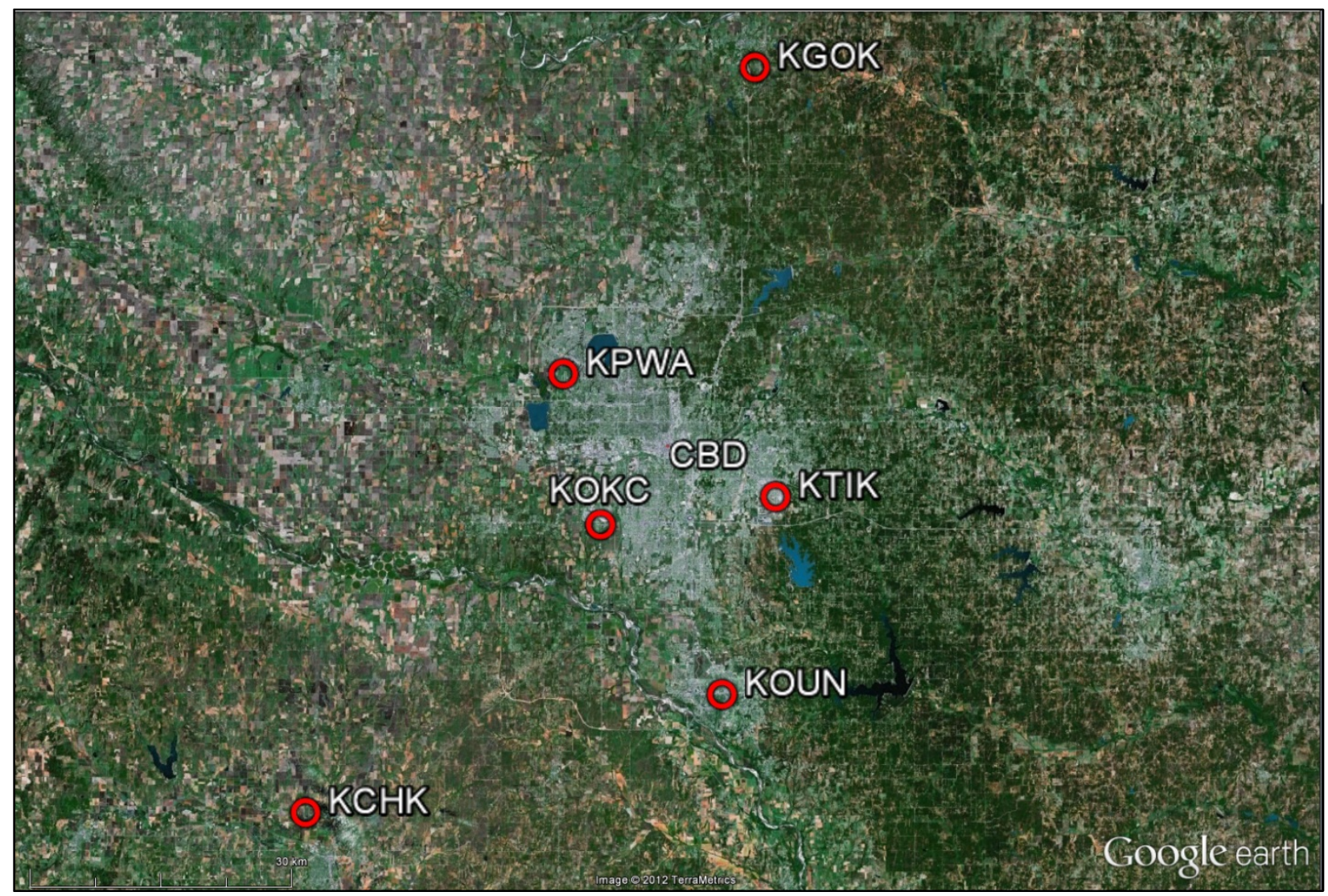

Figure 10. Spatial distribution of the surface meteorological stations assimilated by ADAPT: Wiley Post Airport (call sign KPWA), Chickasha (KCHK), Will Rogers World Airport (KOKC), Tinker Air Force Base (KTIK), and Guthrie-Edmund Regional Airport (KGOK).

\subsection{Surface Data Comparison}

The first step in evaluating the impact of NASA satellite derived surface data on dispersion predictions is to understand the difference in CONTROL run surface data and GSFC/SSC values. As previously discussed, NARAC uses a look-up table to assign spatially-varying surface roughness and displacement height values based on the land-use category of each model grid cell. When building height data are available the corresponding grid-cell values are replaced by values based on these data.

The NARAC land-use categories for the simulation grid are shown in Figure 11 (urban corrections are not included), where red grid cells correspond to different urban land use densities (dark red is high density urban), light green is deciduous forest, brown is cultivated cropland, tan is grassland, and blue is open water. The dominant land use category within the study domain is grassland, which accounts for roughly $45 \%$ of the domain coverage. Cultivated 
cropland and deciduous forest account for another 25 and $18 \%$ of domain coverage respectively. Urban land use accounts for $9 \%$ of the domain while open water covers only $1 \%$ of the domain.

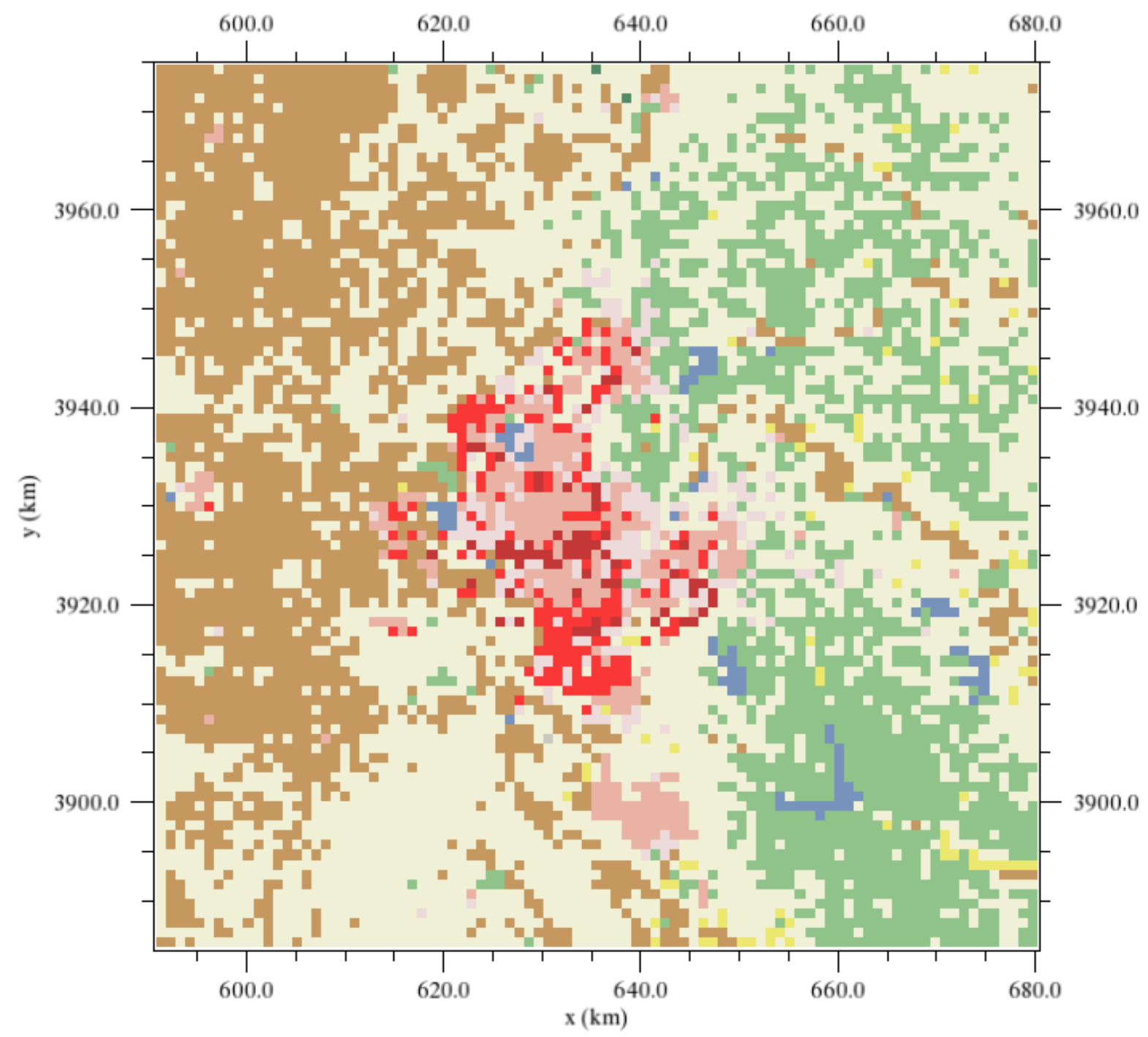

Figure 11. NARAC land use category map for the JU2003 study domain based on NLCD 2006 data. Red grid points correspond to urban land use, light green is deciduous forest, brown is cultivated cropland, tan is grassland, and blue is open water.

\subsubsection{Surface Roughness Length}

A histogram of CONTROL minus GSFC surface roughness length values for all rural grid cells within the evaluation domain is shown in Figure 12(a). Grid cells are defined as rural throughout the evaluation study discussion when the corresponding land use category is anything other than one of the NLCD urban land use categories. Clear systematic differences between CONTROL and NASADATA surface values are apparent. The CONTROL roughness length value for grassland is $0.15 \mathrm{~m}$ while the NASADATA grassland values are typically around 0.045 to $0.055 \mathrm{~m}$ resulting in an average difference of $0.1 \mathrm{~m}$. CONTROL runs use a default roughness length value of $0.10 \mathrm{~m}$ for cultivated cropland while NASADATA has values 
around $0.05 \mathrm{~m}$ resulting in a difference of $0.05 \mathrm{~m}$. Deciduous forest is assigned a roughness length of $0.50 \mathrm{~m}$ in the NARAC look-up table, while nearly $40 \%$ of the NASADATA surface roughness data distribution is between 0.025 and $0.05 \mathrm{~m}$ for the same land-use category, resulting in a maximum difference of $0.45 \mathrm{~m}$. The minimum GSFC derived roughness value for the deciduous forest land use grid points is $0.027 \mathrm{~m}$ and the maximum is $1.47 \mathrm{~m}$ revealing a great deal of variability within this land use category.
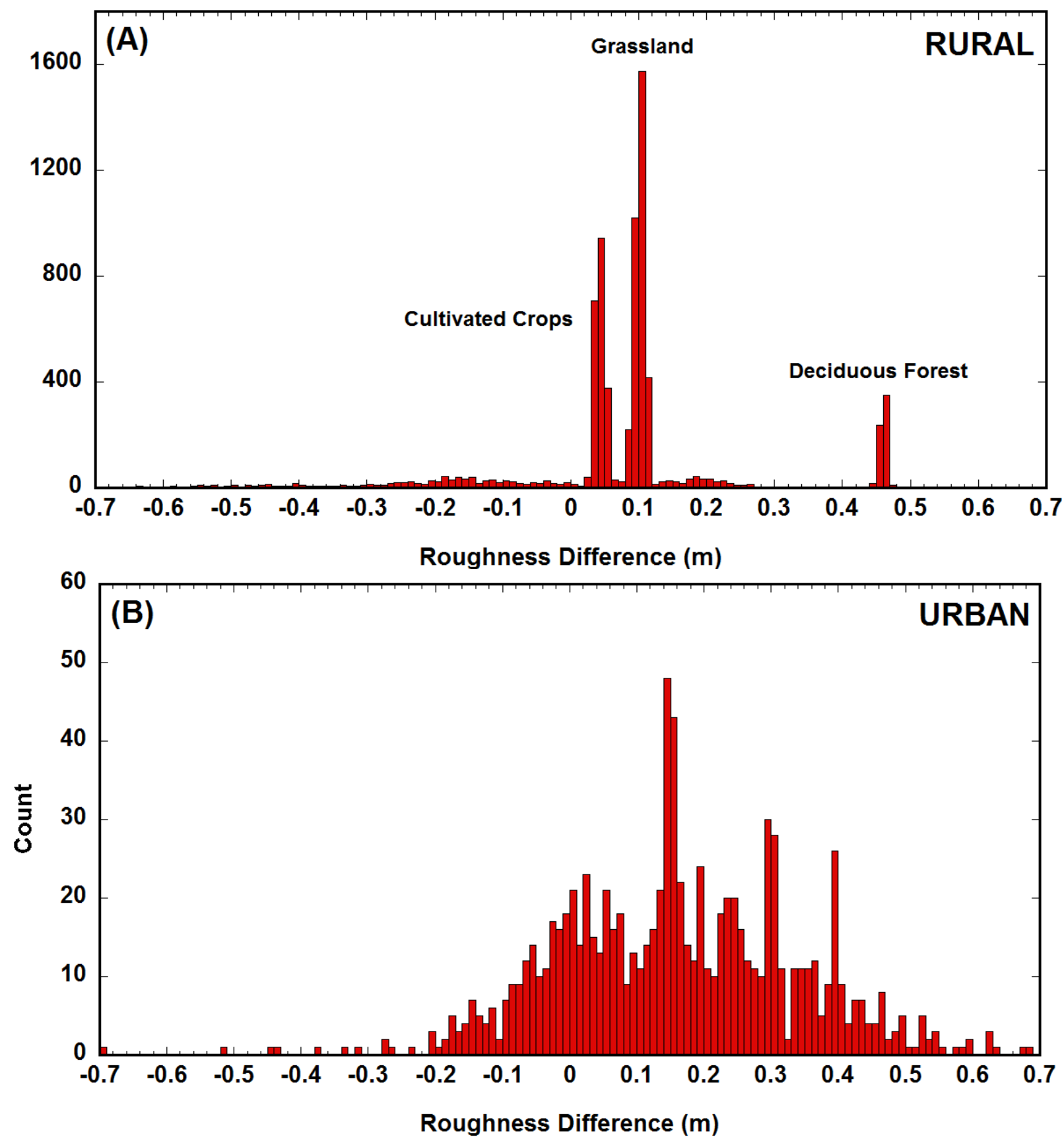

Figure 12. (a) Histogram of CONTROL minus NASADATA surface roughness length values for rural model grid cells. (b) Same as (a) but for urban land use. 
The CONTROL runs calculate urban surface roughness length values from measured building data when available; otherwise the land use look-up table is used to assign default values. When building data are available, the surface roughness length is calculated as $10 \%$ of the grid cell average building height (Grimmond and Oke 1999; Burrian 2005). Building data are available for roughly $75 \%$ of the urban land-use grid cells within the Oklahoma City domain, including the entire Oklahoma City central business district. Urban land-use grid cells away from the city center use the look-up table default values.

The distribution of CONTROL minus NASADATA surface roughness length values for urban land use grid cells is shown in Figure 12(b). The vast majority of the data differences fall within the range of -0.2 to $0.5 \mathrm{~m}$. The largest peak in data difference distribution occurs around $0.15 \mathrm{~m}$ and is associated with NLCD land use category 21, which is urban - developed open space (CONTROL surface roughness length values are around $0.2 \mathrm{~m}$ for this category while the NASADATA values are around 0.04 to 0.06 resulting in the peak at $0.15 \mathrm{~m}$ difference). In general, CONTROL urban surface roughness values are higher than NASADATA values. Excluding deciduous forest land use, differences between CONTROL and NASADATA surface roughness values are higher for urban land use grid points than for rural grid cells.

\subsubsection{Displacement Height}

A histogram of CONTROL minus NASADATA displacement height values for all rural grid cells within the study domain is shown in Figure 13(a). Consistent with the surface roughness analysis, systematic displacement height differences are found for each land use category. The default CONTROL displacement height for grassland is zero, so naturally all NASADATA values for grassland grid points are larger (NASADATA grassland displacement heights are typically around $0.5 \mathrm{~m}$ but values up to $3 \mathrm{~m}$ occur). The 3-m difference occasionally occurs for grassland grid cells that have at least one adjacent forest land-use grid cell. For these grid cells, it is likely that the GSFC method is calculating a displacement height for a grid cell that contains a mixture of grassland and forest resulting in a higher calculated value. For cultivated cropland, the difference in values is around $0.2 \mathrm{~m}$ with the CONTROL value larger than the NASADATA estimate. On average, the default CONTROL deciduous forest displacement height of $7.0 \mathrm{~m}$ is considerably larger than NASADATA values, which are typically only around $0.50 \mathrm{~m}$.

Figure 13(b) shows a histogram of CONTROL minus NASADATA displacement height values for all urban grid cells in the simulation grid. As previously mentioned when building data are available, the CONTROL displacement height is calculated as $50 \%$ of the grid cell average building height (Grimmond and Oke 1999; Burrian 2005). The highest frequency in difference values is around zero, implying that CONTROL and NASADATA urban displacement height values are in reasonable agreement for a number of grid cells. For model grid cells where building data are available, CONTROL and NASADATA urban displacement heights are in reasonable agreement with typical differences in the tenths of meters. However, occasionally 
even when building data are available, the CONTROL values are larger than NASADATA by a few meters. For grid cells where no building is available, CONTROL urban displacements heights are consistently larger than NASADATA values. This highlights the potential value of the NASA satellite derived surface data since it can provide information at urban locations not covered by available building height databases.
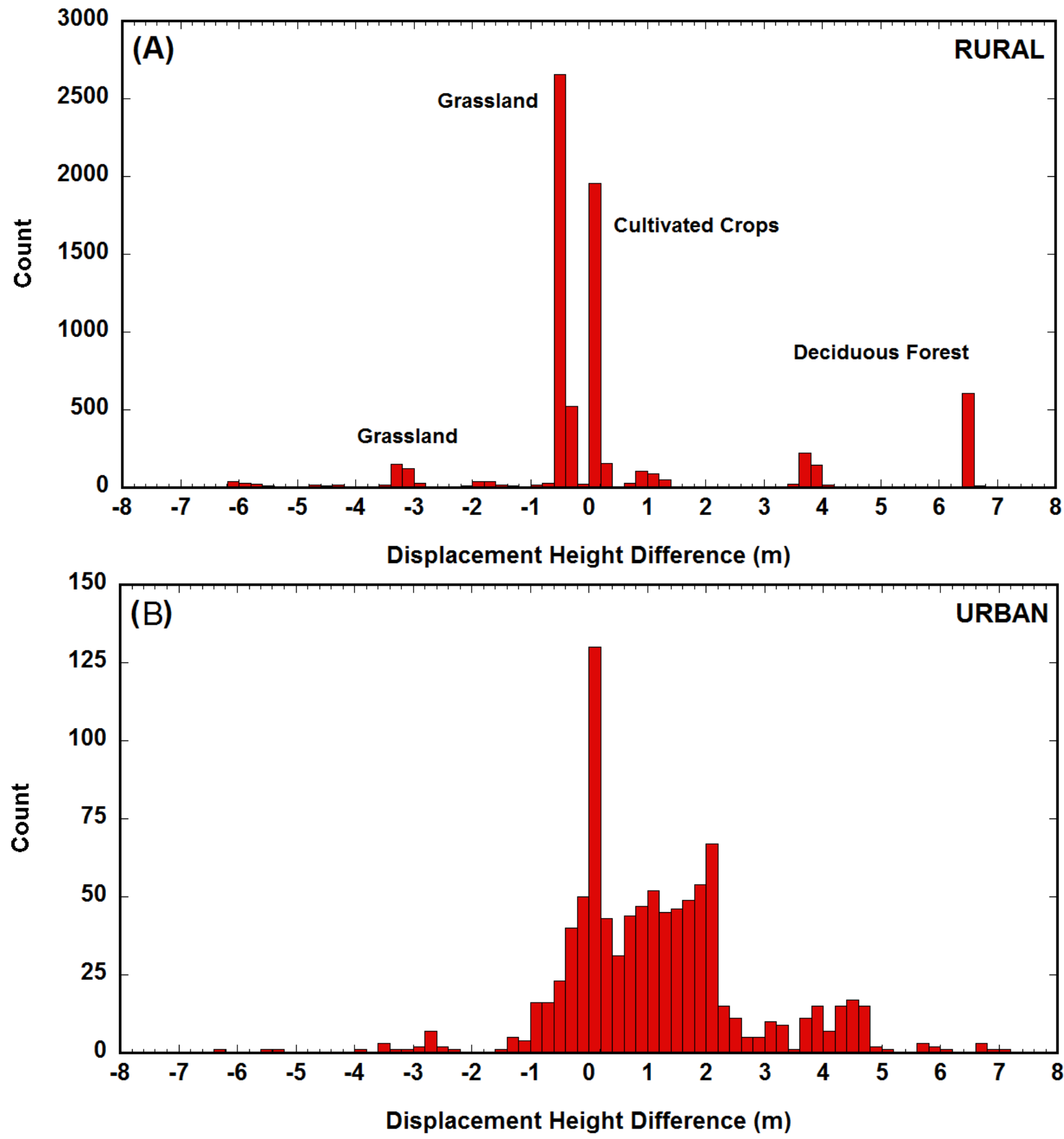

Figure 13. (a) Histogram of CONTROL minus NASADATA displacement height values for rural model grid cells. (b) Same as (a) but for urban land use categories. 


\subsubsection{Surface Data Comparison Summary}

In summary, an examination of both Figures 12 and 13 show that CONTROL surface roughness and displacement heights within the Oklahoma City research domain are generally larger than values NASADATA values. The difference in absolute magnitude is greater for urban land use than for rural areas.

\subsection{Wind Field Comparison}

Differences in CONTROL and NASADATA surface characteristics are expected to translate into a modification of the shape of ADAPT simulated near-surface wind profiles. This section investigates the impact of the use of NASADATA surface data on atmospheric wind modeling.

\subsubsection{Rural Wind Comparison}

A probability distribution of CONTROL minus NASADATA simulated wind speed differences at multiple heights above ground is shown in Figure 14 for all rural grid points in the simulation domain. The wind speed difference at a height level of $0.1 \mathrm{~m}$ is close to zero for the majority of grid cells, since this level is approximately the average roughness length height. At heights of $9.4 \mathrm{~m}$, the wind speed difference is also nearly zero as both the CONTROL and NASADATA runs are dominated by surface wind speed observations that are provided at $10 \mathrm{~m}$ above ground. CONTROL run wind speeds are typical lower than NASADATA wind speeds by between 0.25 to $1.5 \mathrm{~m} / \mathrm{s}$ at the 2.2 and $5.3 \mathrm{~m}$ levels. This is expected since CONTROL rural surface roughness lengths are larger than NASADATA values and the larger surface stress results in lower wind speeds at these levels. Starting at the $15.1 \mathrm{~m}$ level, CONTROL winds become larger than corresponding NASADATA wind speeds with of around $0.2 \mathrm{~m} / \mathrm{s}$. For heights between 30 and $131 \mathrm{~m}$ above ground, the average CONTROL wind speed is on average 0.3 to $0.4 \mathrm{~m} / \mathrm{s}$ larger than NASADATA winds. Since the average wind speed during the JU2003 IOP days included in this study is around $6.5 \mathrm{~m} / \mathrm{s}$, use of NASADATA surface values increased the simulated wind speed between 30 and $131 \mathrm{~m}$ above ground by around $5 \%$. Wind speeds above $~ 200 \mathrm{~m}$ (approximate height of daytime surface layer) are not impacted in rural areas as expected (not shown).

\subsubsection{Urban Wind Comparison}

Figure 15 shows the distributions of CONTROL minus NASADATA simulated wind speed differences occurring at different model levels for all urban grid cells. There is a higher likelihood of significant CONTROL-NASADATA discrepancies when compared with the rural distribution which is to be expected since the difference in CONTROL and NASADATA surface roughness and displacement heights is greater for urban areas. However, the trends are similar to the rural case, with CONTROL winds in the urban area lower by 0.5 and $1.0 \mathrm{~m} / \mathrm{s}$ than NASADATA winds at the lowest model height levels (below $10 \mathrm{~m}$ ). Above $15.1 \mathrm{~m}$, CONTROL run wind speeds again become larger than NASADATA winds with the difference increasing from 0.1 to $0.6 \mathrm{~m} / \mathrm{s}$ at $22.9 \mathrm{~m}$ to 0.3 to $1.2 \mathrm{~m} / \mathrm{s}$ at $95.4 \mathrm{~m}$. Above approximately $250 \mathrm{~m}$ height in the urban region, winds speeds are not significantly impacted by the differences in surface data 
values (not shown). Differences in simulated wind speeds are much greater for the urban region of the research domain than for rural grid points. Differences in simulated air concentration therefore are expected to be larger in the urban area.

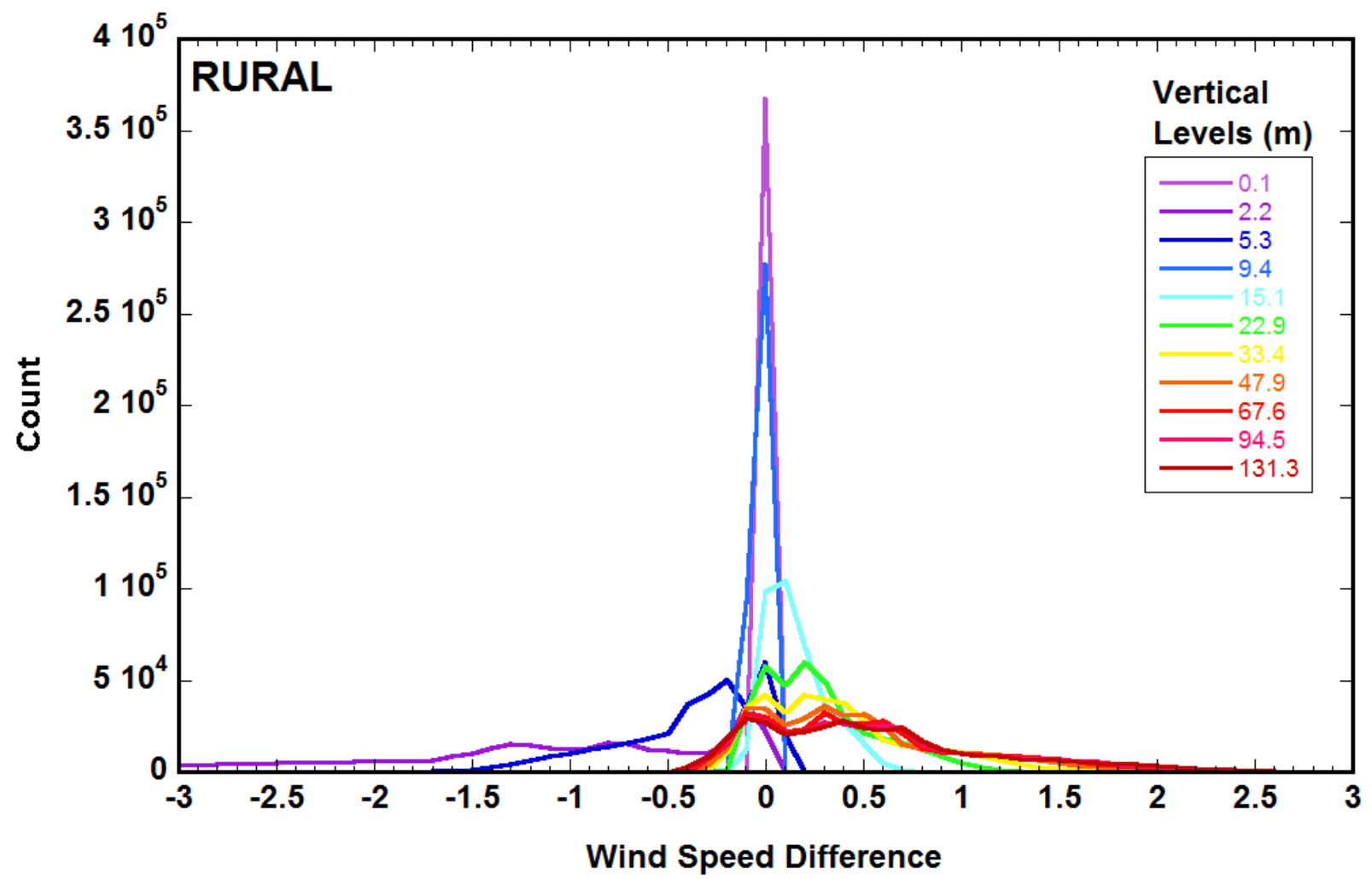

Figure 14. Distribution of CONTROL minus NASADATA simulated wind speed differences at multiple heights above ground for urban grid points. 


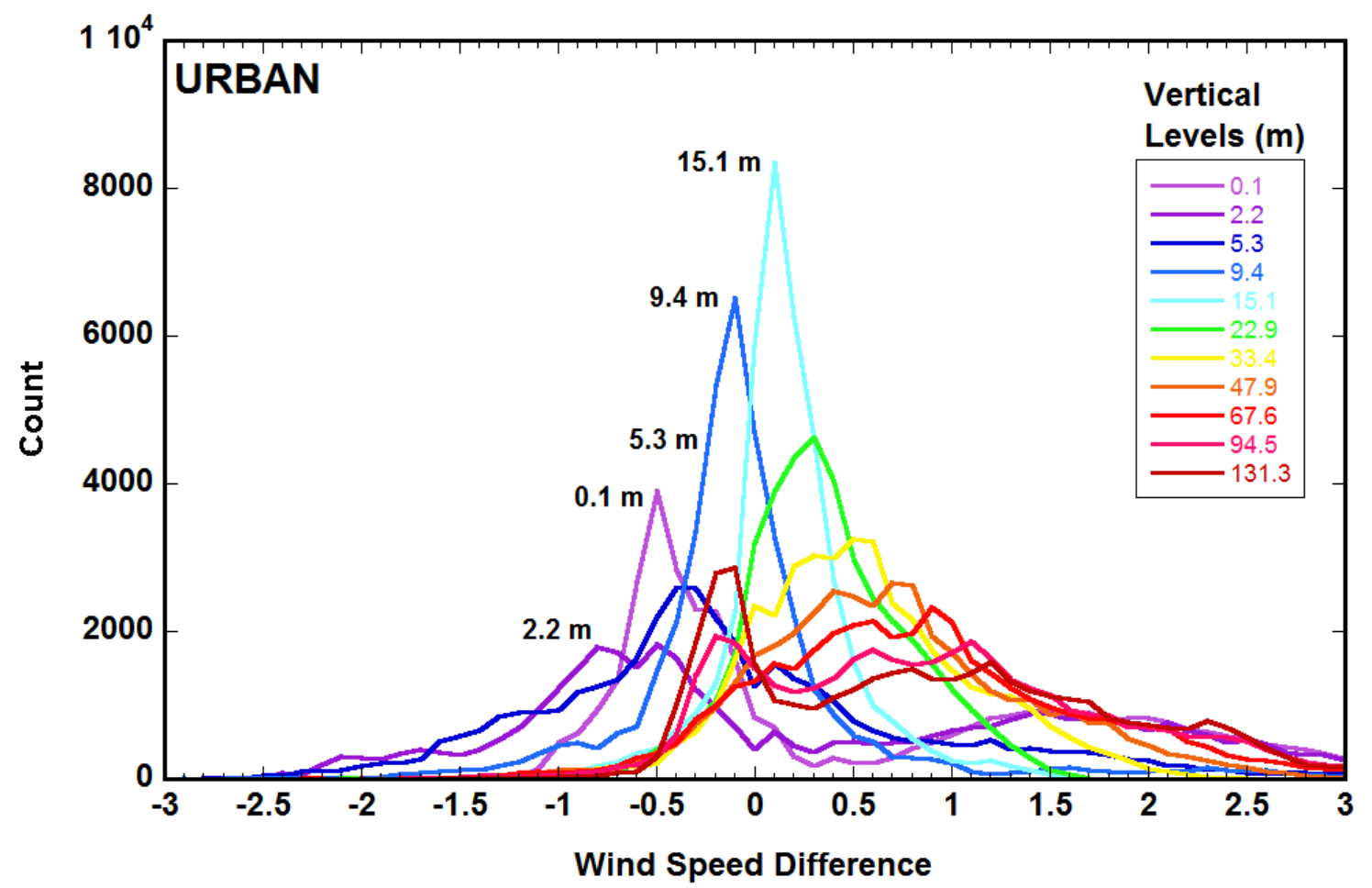

Figure 15. Distribution of CONTROL minus NASADATA simulated wind speed differences at multiple heights above ground for rural grid points.

\subsection{Statistical Comparison Metrics}

The statistical metrics used for the dispersion evaluation study include the standard fraction of predicted values within a factor or 2, 5, and 10 of the observed concentration (FAC2, FAC5, and FAC10), fractional bias (FB), normalized mean square error (NMSE), and geometric mean bias (MG) (Chang and Hanna 2004; Sawyer 2007).

A FAC2/5/10 value of $100 \%$ represents the best possible model performance at predicted concentrations that fall within the specified range. FAC2/5/10 are calculated by:

FAC2: fraction of values for which $0.5 \leq C_{p} / C_{0} \leq 2$

FAC5: fraction of values for which $0.2 \leq C_{p} / C_{0} \leq 5$

FAC10: fraction of values for which $0.1 \leq C_{p} / C_{0} \leq 10$

where $C_{o}$ is observed concentration and $C_{p}$ denotes predicted concentration.

The FB measures whether a predicted data distribution over or underestimates observed values (FB ranges from -2 to 2 with zero indicating no bias) (Yadav and Sharan 1996) and is defined as:

$$
\mathrm{FB}=\frac{\left(\overline{\mathrm{C}}_{0}-\overline{\mathrm{C}}_{\mathrm{p}}\right)}{0.5\left(\overline{\mathrm{C}}_{0}+\overline{\mathrm{C}}_{\mathrm{p}}\right)}
$$


The MG is a logarithmic based metric that is desirable when a wide range of values (e.g. over several orders of magnitude) are present in an observed data distribution. An MG value of 1.0 represents a 'perfect model' (Hanna 1991). MG is defined as:

$$
\mathrm{MG}=\exp \left(\overline{\ln C_{0}}-\overline{\ln C_{p}}\right)
$$

NMSE describes the overall difference between predicted and observed concentration with a value of zero representing perfect model performance. NMSE is calculated by:

$$
\text { NMSE }=\frac{\left(\overline{\mathrm{C}_{\mathrm{o}}-\mathrm{C}_{\mathrm{p}}}\right)^{2}}{\overline{\mathrm{C}}_{0} \overline{\mathrm{C}}_{\mathrm{p}}}
$$

\subsection{Dispersion Evaluation}

This section presents a comparison of predicted air concentrations from CONTROL and NASADATA dispersion simulations with the corresponding JU2003 IOP measured 30-minute average surface air concentration measurements.

CONTROL and NASADATA FAC2, FAC5, and FAC10 statistics for each of the 9 dispersion test cases are summarized in Table 3. The CONTROL runs have more predicted concentrations within a factor of 2 (FAC2) of observed values than NASADATA runs for all but one of the dispersion simulations. The greatest difference occurs for IOP 2 - Trial 1, where CONTROL FAC2 is superior to NASADATA by around 6\%. However, the average FAC2 value for CONTROL and NASADATA runs from all IOP dispersion releases is $49.3 \%$ and $48.0 \%$ respectively, with an average difference of only around 1\%. FAC5 and FAC10 statistics convey a similar story with the CONTROL runs performing better than the NASADATA runs by about $3 \%$ and $1.5 \%$ respectively. The greatest difference between the runs based on FAC5 and FAC10 is $5-8 \%$, for to IOP2-Trial1 and IOP2-Trial2.

Table 3. Fraction (\%) of CONTROL and NASADATA predicted air concentrations within a factor of 2 (FAC2), 5 (FAC5), and 10 (FAC10) of JU2003 CBD and sensor arc measured concentrations.

\begin{tabular}{|l|c|c|c|c|c|c|}
\hline IOP Number & $\begin{array}{c}\text { CONTROL } \\
\text { FAC2 (\%) }\end{array}$ & $\begin{array}{c}\text { NASA- } \\
\text { DATA } \\
\text { FAC2 (\%) }\end{array}$ & $\begin{array}{c}\text { CONTROL } \\
\text { FAC5 (\%) }\end{array}$ & $\begin{array}{c}\text { NASA- } \\
\text { DATA } \\
\text { FAC5 (\%) }\end{array}$ & $\begin{array}{c}\text { CONTROL } \\
\text { FAC10 (\%) }\end{array}$ & $\begin{array}{c}\text { DASA- } \\
\text { FAC10 (\%) }\end{array}$ \\
\hline IOP 2 - Trial 1 & 26.7 & 20.9 & 76.7 & 70.9 & 86.0 & 77.9 \\
\hline IOP 2 - Trial 2 & 43.0 & 39.0 & 81.0 & 74.0 & 87.0 & 83.0 \\
\hline IOP 2 - Trial 3 & 51.5 & 51.5 & 80.2 & 76.2 & 83.2 & 82.2 \\
\hline IOP 3 - Trial 1 & 51.5 & 49.5 & 76.2 & 72.3 & 85.1 & 82.2 \\
\hline IOP 3 - Trial 2 & 54.5 & 52.5 & 77.2 & 80.2 & 88.1 & 87.1 \\
\hline
\end{tabular}




\begin{tabular}{|c|c|c|c|c|c|c|}
\hline IOP 3 - Trial 3 & 40.6 & 43.6 & 67.3 & 67.3 & 78.2 & 80.2 \\
\hline IOP 4 - Trial 1 & 52.5 & 50.5 & 75.2 & 74.3 & 81.2 & 81.2 \\
\hline IOP 4 - Trial 2 & 62.4 & 60.4 & 90.1 & 88.1 & 93.1 & 95.0 \\
\hline IOP 4 - Trial 3 & 62.1 & 60.2 & 84.5 & 80.6 & 92.2 & 90.3 \\
\hline $\begin{array}{c}\text { Average } \\
\text { (all data) }\end{array}$ & 49.3 & 48.0 & 78.8 & 76.1 & 86.0 & 84.5 \\
\hline
\end{tabular}

Based on the FAC analysis, the CONTROL runs are only slightly better (2\%) at predicting air concentrations for the majority of dispersion cases. As Flaherty et al. (2007) calculated an air concentration analyzer instrument error of between $\pm 3-6 \%$ during JU2003 based on a coefficient of variability analysis, the average difference in FAC values between CONTROL and NASADATA runs is not statistically significant.

FB, NMSE, and MG statistics for each of the 9 CONTROL and NASADATA dispersion test cases are shown in Table 4 . The average FB value over all the dispersion runs is -0.17 for the CONTROL run and -0.03 for NASADATA cases. Both values are negative implying that both CONTROL and NASADATA runs have a tendency to overestimate the observed concentration. Since the NASADATA average FB is closer to zero (perfect model result), the GSFC/SSC surface data results in a slightly lower overestimation bias. However, it should be noted that there is a large amount of run specific variability in the FB values with the NASADATA runs closer to zero (i.e. less bias) for only 6 out of the 9 test cases.

Table 4. Fractional bias (FB), normalized mean square error (NMSE), and geometric mean bias (MG) statistics for the CONTROL and NASADATA simulations.

\begin{tabular}{|l|c|c|c|c|c|c|}
\hline IOP Number & $\begin{array}{c}\text { CONTROL } \\
\text { FB }\end{array}$ & $\begin{array}{c}\text { NASA- } \\
\text { DATA } \\
\text { FB }\end{array}$ & $\begin{array}{c}\text { CONTROL } \\
\text { MG }\end{array}$ & $\begin{array}{c}\text { NASA- } \\
\text { DATA } \\
\text { MG }\end{array}$ & $\begin{array}{c}\text { CONTROL } \\
\text { NMSE }\end{array}$ & $\begin{array}{c}\text { NASA- } \\
\text { DATA } \\
\text { NMSE }\end{array}$ \\
\hline IOP 2 - Trial 1 & -0.13 & -0.25 & 0.89 & 0.62 & 1.01 & 1.24 \\
\hline IOP 2 - Trial 2 & -0.21 & 0.15 & 0.78 & 0.67 & 2.64 & 3.67 \\
\hline IOP 2 - Trial 3 & -0.26 & 0.22 & 0.65 & 0.60 & 2.30 & 2.08 \\
\hline IOP 3 - Trial 1 & -0.24 & 0.14 & 0.57 & 0.53 & 3.66 & 2.51 \\
\hline IOP 3 - Trial 2 & -0.20 & 0.08 & 0.55 & 0.52 & 4.13 & 1.63 \\
\hline IOP 3 - Trial 3 & -0.21 & -0.20 & 0.39 & 0.38 & 0.56 & 0.43 \\
\hline IOP 4 - Trial 1 & -0.16 & -0.15 & 0.64 & 0.56 & 0.54 & 0.45 \\
\hline IOP 4 - Trial 2 & -0.10 & -0.17 & 0.74 & 0.70 & 0.96 & 2.78 \\
\hline IOP 4 - Trial 3 & -0.06 & -0.19 & 0.61 & 0.59 & 0.83 & 1.13 \\
\hline
\end{tabular}




\begin{tabular}{|l|l|l|l|l|l|l|}
\hline $\begin{array}{l}\text { Average } \\
\text { (all data) }\end{array}$ & -0.17 & -0.03 & 0.63 & 0.57 & 2.55 & 2.31 \\
\hline
\end{tabular}

The overall average MG values for the CONTROL and NASADATA dispersion simulations are 0.63 and 0.57 respectively. Since an MG value of 1.0 represent a 'perfect model', the CONTROL run performs better than the NASADATA run for this metric. The MG is a logarithmic metric (unlike FB and NMSE) that lessens the contribution of extreme values within a data distribution. This implies the CONTROL run performs better at predicting the overall dispersion pattern but that the NASADATA runs are on average better at predicting the extremes within the observed concentration data as evidenced by the FB performance.

The average NMSE values for all the CONTROL and NASADATA dispersion simulations are 2.55 and 2.31 respectively. Since NMSE is a normalized measure of model error, the smaller NASADATA value represents a modest improvement of around $9 \%$ in concentration prediction skill, an amount that is greater than estimated measurement error. However as for the FB metric, when comparing individual dispersion runs, NASADATA NMSE values are only lower for 5 out of the 9 cases. A significant portion of the NASADATA average-NMSE improvement comes from IOP 3-Trial 2 where the CONTROL run has a large NMSE value of 4.13 and the NASADATA value is only 1.63. This lack of consistency in suggests that the difference between the two sets of simulations is not significant.

CONTROL and NASADATA normalized mean square error (NMSE) statistics calculated separately for concentration data from the central business district (CBD) and the arcs at 1, 2, and $4 \mathrm{~km}$ are shown in Table 5. Both the CONTROL and NASADATA simulations have lower average NMSE values for the CBD than for the sensor arcs, indicating better model performance near the source location. The CONTROL run has an average NMSE in the CBD of 1.39 and an average value of 1.78 on the sensor arcs, while the NASADATA runs have a CBD average NMSE of 1.27 and a value of 2.70 for the arcs. The lower NMSE value in the CBD for the NASADATA simulations indicates the model is predicting near source concentrations somewhat better than the CONTROL run. In contrast, the CONTROL runs have lower NMSE values along the arcs than NASADATA for 8 out of the 9 dispersion test cases implying that the CONTROL run is performing better than NASADATA along the arcs. However as with the prior comparisons, there is considerable variability between different IOP trials.

Table 5. Comparison of CONTROL and NASADATA normalized mean square error (NMSE) statistics calculated separately using measured concentration data from the central business district (CBD) and from data along the 1, 2, and $4 \mathrm{~km}$ sensor arcs.

\begin{tabular}{|c|c|c|c|c|}
\hline IOP Number & $\begin{array}{c}\text { CONTROL } \\
\text { NMSE (CBD) }\end{array}$ & $\begin{array}{c}\text { NASADATA } \\
\text { NMSE (CBD) }\end{array}$ & $\begin{array}{c}\text { CONTROL } \\
\text { NMSE (ARCS) }\end{array}$ & $\begin{array}{c}\text { NASADATA } \\
\text { NMSE (ARCS) }\end{array}$ \\
\hline IOP 2 - Trial 1 & 0.48 & 0.58 & 7.70 & 8.01 \\
\hline IOP 2 - Trial 2 & 1.41 & 1.96 & 0.96 & 0.84 \\
\hline IOP 2 - Trial 3 & 1.66 & 1.16 & 0.39 & 0.82 \\
\hline
\end{tabular}




\begin{tabular}{|c|c|c|c|c|}
\hline IOP 3 - Trial 1 & 1.87 & 1.30 & 2.72 & 4.10 \\
\hline IOP 3 - Trial 2 & 2.36 & 0.94 & 0.90 & 0.97 \\
\hline IOP 3 - Trial 3 & 0.32 & 0.25 & 3.54 & 4.23 \\
\hline IOP 4 - Trial 1 & 0.30 & 0.25 & 1.47 & 2.37 \\
\hline IOP 4 - Trial 2 & 0.54 & 1.57 & 0.26 & 0.31 \\
\hline IOP 4 - Trial 3 & 0.47 & 0.64 & 1.00 & 1.45 \\
\hline $\begin{array}{c}\text { Average } \\
\text { (all data) }\end{array}$ & 1.39 & 1.27 & 1.78 & 2.70 \\
\hline
\end{tabular}

The CONTROL runs have an average MG in the CBD of 0.37 and an average value of 1.14 for the arcs, while the NASADATA runs have an average MG value of 0.30 in the CBD and a value of 1.15 for the arcs. Both simulations have better MG values (closer to 1.0) for the arcs than the CBD indicating the runs are performing better relative to this metric at locations some distance away from the source (Table 6). The differences between CONTROL and NASADATA MG values for the sensor arcs are small and not statistically significant. However, the CONTROL runs perform better in the CBD for all of the test cases based on the MG statistics indicating better near source concentration prediction when the impact of extreme observed concentration values is reduced.

Examining both MG and NMSE model performance in the CBD versus the sensor arcs results in an inconclusive answer as to which set of runs performs the best. For the NMSE metric, the CONTROL simulations are significantly better along the sensor arcs with comparable performance with the NASADATA runs in the CBD. In contrast, the MG metric indicates the CONTROL run performs somewhat better that the NASADATA runs in the CBD with similar performance for the sensor arcs. This implies the two sets of model runs are performing with approximately the same general level of skill.

Table 6. Comparison of CONTROL and NASADATA geometric mean bias (MG) statistics calculated separately using measured concentration data from the central business district (CBD) and from data along the 1, 2, and $4 \mathrm{~km}$ sensor arcs.

\begin{tabular}{|c|c|c|c|c|}
\hline IOP Number & $\begin{array}{c}\text { CONTROL } \\
\text { MG (CBD) }\end{array}$ & $\begin{array}{c}\text { NASADATA } \\
\text { MG (CBD) }\end{array}$ & $\begin{array}{c}\text { CONTROL } \\
\text { MG (ARCS) }\end{array}$ & $\begin{array}{c}\text { NASADATA } \\
\text { MG (ARCS) }\end{array}$ \\
\hline IOP 2 - Trial 1 & 0.21 & 0.11 & 3.12 & 2.77 \\
\hline IOP 2 - Trial 2 & 0.32 & 0.22 & 2.15 & 2.34 \\
\hline IOP 2 - Trial 3 & 0.28 & 0.25 & 1.77 & 1.74 \\
\hline IOP 3 - Trial 1 & 0.38 & 0.33 & 0.85 & 0.84 \\
\hline IOP 3 - Trial 2 & 0.44 & 0.40 & 0.73 & 0.71 \\
\hline IOP 3 - Trial 3 & 0.30 & 0.27 & 0.53 & 0.59 \\
\hline IOP 4 - Trial 1 & 0.41 & 0.36 & 1.08 & 0.95 \\
\hline
\end{tabular}




\begin{tabular}{|c|c|c|c|c|}
\hline IOP 4 - Trial 2 & 0.58 & 0.49 & 0.99 & 1.10 \\
\hline IOP 4-Trial 3 & 0.49 & 0.43 & 0.78 & 0.88 \\
\hline $\begin{array}{c}\text { Average } \\
\text { (all data) }\end{array}$ & 0.37 & 0.30 & 1.14 & 1.16 \\
\hline
\end{tabular}

Both CONTROL and NASADATA simulations produce similar air concentration patterns. Predicted 30-minute averaged plume concentrations (contours) overlaid with sensor measurement for the JU2003 IOP 3, trial 1 and IOP 3, trial 2 releases are shown in Figures 16 and 17. Although these simulations have among the largest differences in the NMSE error statistics, the overall concentration patterns are qualitatively similar. The primary visible difference between the plots is that the NASADATA plumes are slightly narrower than the CONTROL run, with the 5.0E- $6 \mathrm{~g} \mathrm{~m}^{3}$ plume contour about half a city block $(\sim 50 \mathrm{~m})$ wider in the CONTROL simulations. There is significantly greater horizontal and vertical diffusion in the CONTROL runs resulting from the larger surface stresses induced by higher urban surface roughness and displacement heights. Near-surface wind speeds are also higher for the NASADATA runs. Both effects result in narrower ground level air concentration plumes. Since sizable differences in statistical evaluation metrics can occur when concentrations sensors are located where large horizontal gradients in air concentration are observed, the differences observed in the quantitative metrics are likely due to plume edge effects and do not indicate a statistically significant difference in the overall plume patterns.

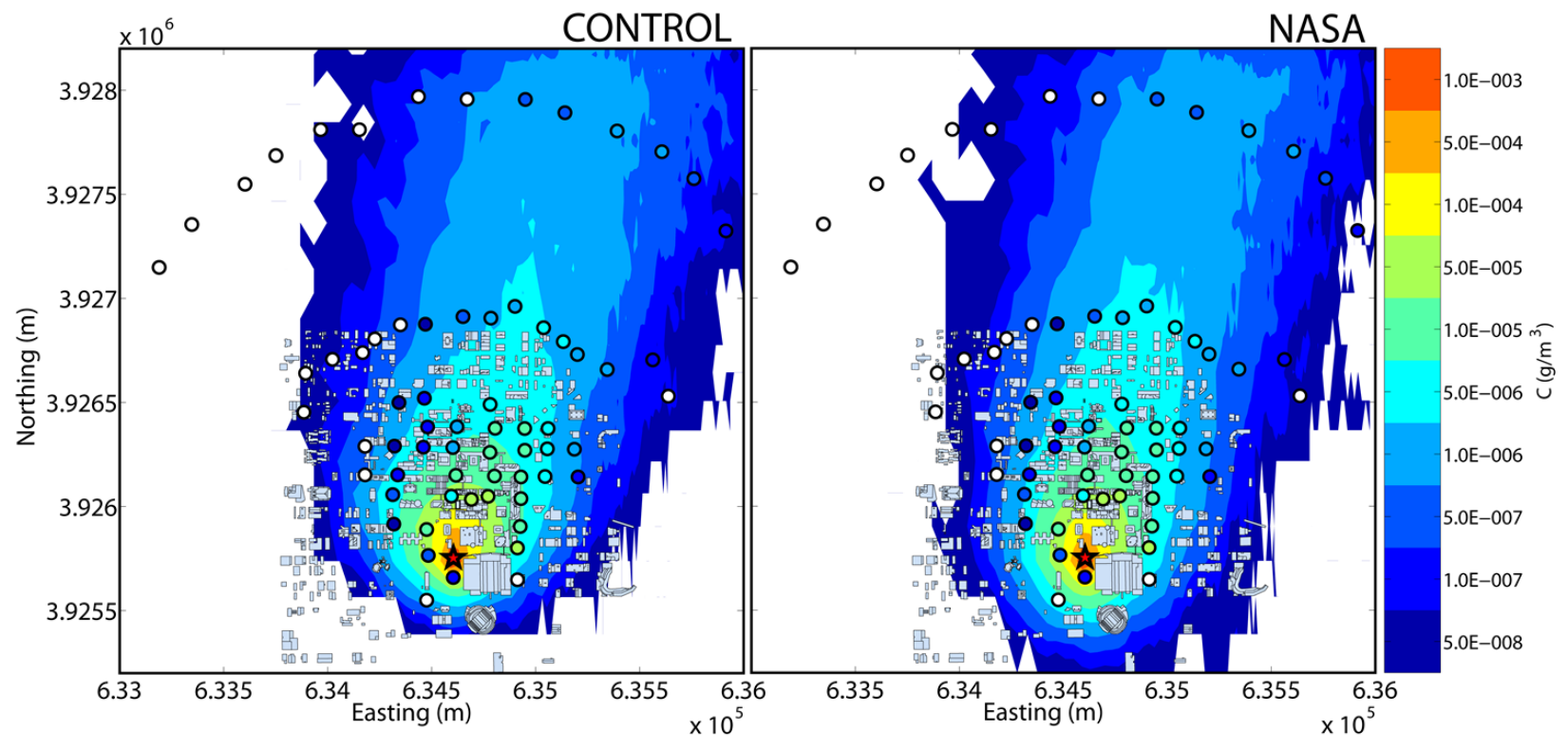

Figure 16. CONTROL and NASADATA predicted 30-minute averaged plume concentrations (contours) overlaid with sensor measurement for the JU2003 IOP 3, trial 1 atmospheric release. 


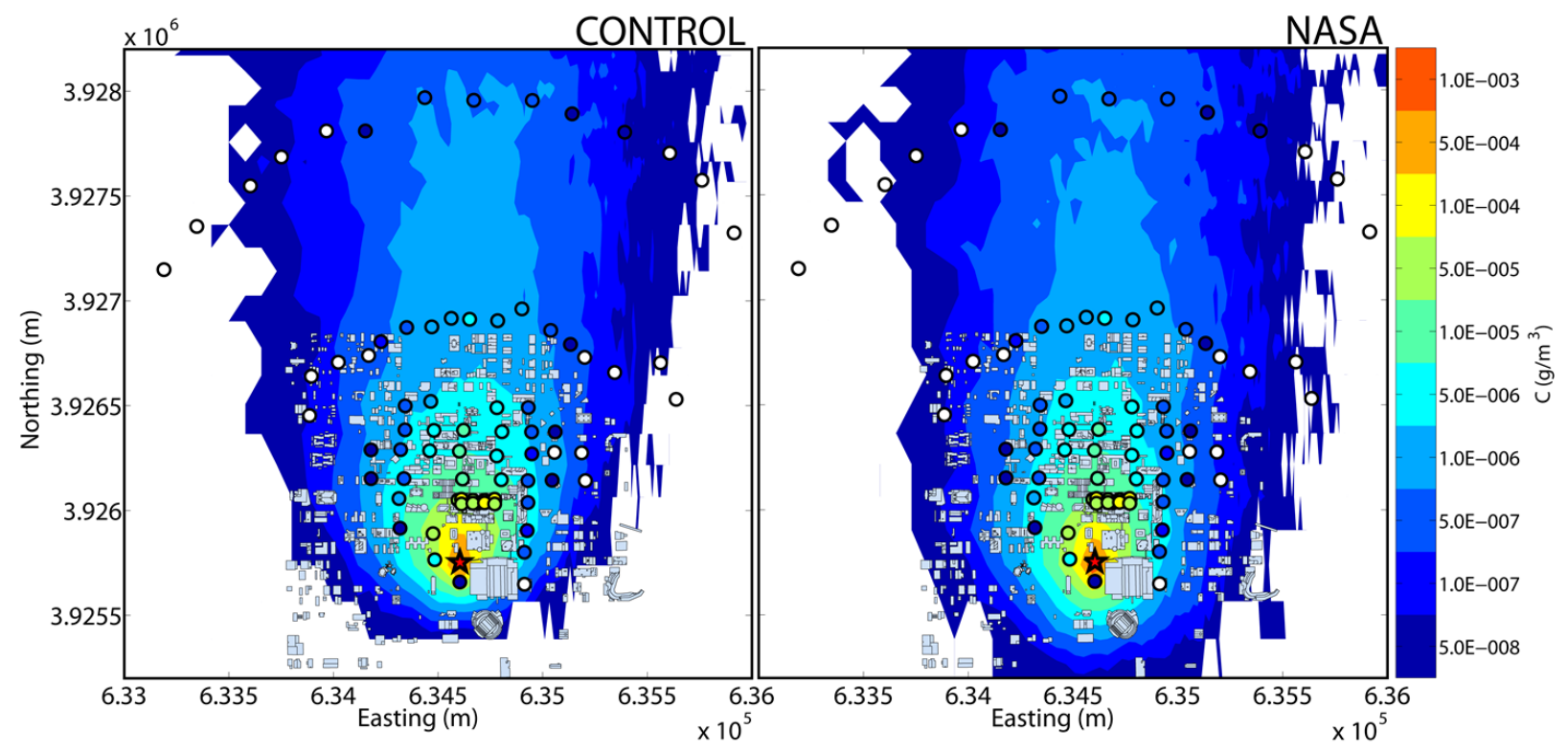

Figure 17. CONTROL and NASADATA predicted 30-minute averaged plume concentrations (contours) overlaid with sensor measurement for the JU2003 IOP 3, trial 2 atmospheric release.

The statistical and graphical evaluation of the CONTROL and NASADATA dispersion runs does not reveal a consistently better performing set of runs. The average percent difference in FAC2/5/10 values falls within the range of instrument error indicating no statistical significance. The MG metric suggests the CONTROL runs perform better, while in contrast, the NMSE metric indicates the NASADATA runs perform statistically better. The lack of consistency in the statistical metrics and the overall similarity in plume patterns implies the two sets of model runs are performing with the same general level of dispersion prediction skill.

\subsection{Peak Air Concentration Comparison}

The impact of using NASADATA surface data on simulated peak surface air concentrations is investigated. Peak air concentration is an important parameter for emergency response modeling because it is critical to determining health effects associated with many chemical releases. Predicted peak 30-minute average surface air concentrations for each of the 9 JU2003 CONTROL and NASADATA evaluation dispersion releases are shown in Figure 18. NASADATA simulated peak concentrations are $35-49 \%$ (with a median of $44 \%$ ) higher than CONTROL peak concentrations for all nine atmospheric release test cases. The difference in the peak concentrations is best explained by the diffusion and wind speed differences discussed in Section 5.5. Near-surface NASADATA simulated wind speeds in urban areas are typically 0.5 to $1.0 \mathrm{~m} / \mathrm{s}$ higher than CONTROL wind speeds resulting in narrower plumes (as evident in Figures 16 - 17) and higher centerline concentrations. CONTROL urban surface roughness and displacement heights are larger than NASADATA which produces increased diffusion and lower air concentrations. Although there are no peak air concentration observations from 
JU2003 to evaluate these predictions, the results indicate the sensitivity of near source peak concentrations to choice of surface data.

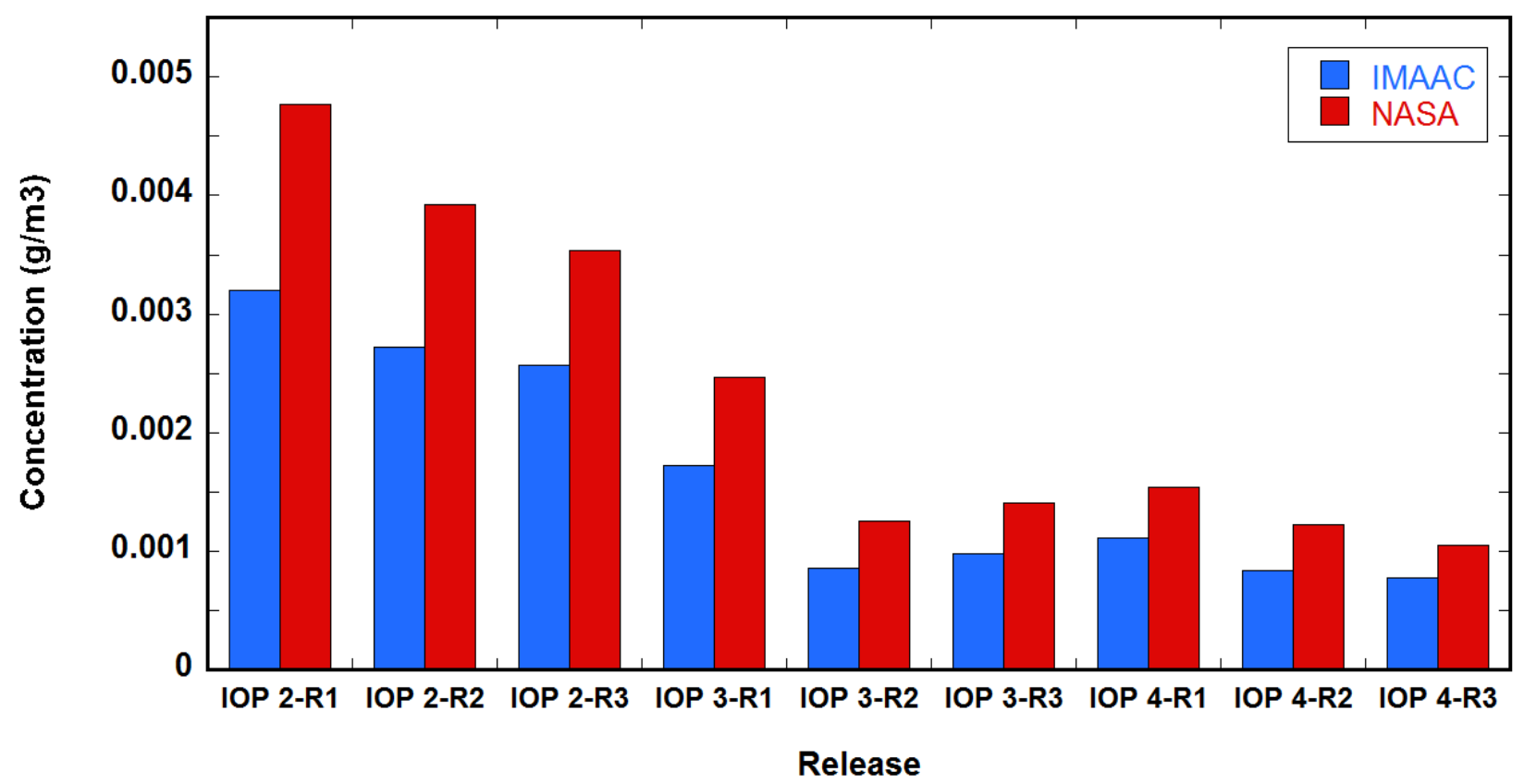

Figure 18. Comparison of peak 30-minute average air concentration between CONTROL (blue) and NASADATA (red) surface data simulation for all 9 dispersion evaluation test cases.

\subsection{Rural Concentration Comparison}

In addition to investigating the impact of the combined GSFC/SSC surface characteristic data on dispersion predictions in the urban region of Oklahoma, we separately evaluate the influence on dispersion predictions in the surrounding rural area. Since no JU2003 air concentrations measurements are available outside of the urban core of $\mathrm{OKC}$, this analysis consists of a modelto-model comparison. A new set of HYBRID dispersion runs are made that use the same surface data as the CONTROL runs in the urban region and GSFC-derived surface roughness and displacement values for the rural areas. The HYBRID runs remove the influence of SSC surface data values in the urban area, so that the sensitivity of predicted rural air concentrations to GSFC rural values can be isolated. The CONTROL and HYBRID predicted air concentration comparisons are made at increments of $100 \mathrm{~m}$ in the downwind radial direction from the release location in the Oklahoma City central business district.

The median percentage difference between CONTROL and HYBRID centerline concentrations in the rural regions surrounding OKC for each dispersion case is shown in Table 7. Observed meteorological conditions during each release are also provided for reference. For most of the test cases, the difference between CONTROL and HYBRID centerline concentrations is within $\pm 10 \%$. This indicates the GFSC-derived land-surface data has a small impact on rural centerline concentrations. However, there is one outlier case, IOP2-Trial 3, for which the difference is 
51.5\% with CONTROL run predicted concentrations much lower than HYBRID concentrations. A possible explanation for this discrepancy is the wind direction during IOP2-Trial 3 that had an easterly component unlike the other releases. However, additional analysis is needed to fully understand why the rural air concentration for IOP2-Trial 3 is more sensitive to surface data choice than the other releases.

An illustrative comparison of CONTROL and HYBRID centerline air concentrations for IOP 2Trial 3, IOP 4-Trial 2, and IOP 4-Trial 3 releases is shown in Figure 19 (note the logarithmic scale for the air concentrations). The predicted concentrations in the Oklahoma City urban region (highlighted in gray) are in close agreement since the same urban surface data was used in both calculations. For IOP 2-Trial 3 shown in Figure 19(a), CONTROL air concentrations (blue line) are generally below the HYBRID values (red line). As discussed above, the median percent difference in CONTROL and HYBRID concentrations for IOP 2-Trial 3 is $51.5 \%$ making this an excellent example of how predicted concentrations can be highly sensitive to surface characteristic data. Centerline concentrations for IOP 4-Trial 2, and IOP 4-Trial 3 shown in Figure 19(b) and (c) represent dispersion cases where using NASADATA surface data results in only a marginal difference in centerline air concentrations. The average centerline concentration difference for these releases is -6.3 and $-8.2 \%$. No systematic impact of NASADATA surface data on predicted rural centerline concentrations is evident. At some distances the CONTROL run predicted concentration is greater while at other distances HYBRID concentrations are higher.

Table 7. Median difference in CONTROL minus HYBRID centerline air concentrations in rural regions. The corresponding meteorological conditions during each dispersion simulation are shown for reference.

\begin{tabular}{|c|c|c|c|c|}
\hline IOP Number & Release Time & $\begin{array}{c}\text { Wind } \\
\text { Speed }(\mathrm{m} / \mathrm{s})\end{array}$ & $\begin{array}{c}\text { Wind Dir. } \\
\text { (degrees) }\end{array}$ & $\begin{array}{c}\text { Concentration } \\
\text { Difference (\%) }\end{array}$ \\
\hline IOP 2 - Trial 1 & 2 July 16:00 - 16:30 UTC & 5.0 & 234 & -4.4 \\
\hline IOP 2 - Trial 2 & 2 July 18:00 - 18:30 UTC & 4.5 & 200 & 3.1 \\
\hline IOP 2 - Trial 3 & 2 July 20:00 - 20:30 UTC & 5.2 & 171 & -51.5 \\
\hline IOP 3 - Trial 1 & 7 July 16:00 - 16:30 UTC & 7.4 & 203 & 5.8 \\
\hline IOP 3 - Trial 2 & 7 July 18:00 - 18:30 UTC & 6.5 & 190 & 1.9 \\
\hline IOP 3 - Trial 3 & 7 July 20:00 - 20:30 UTC & 7.6 & 195 & 13.5 \\
\hline IOP 4 - Trial 1 & 9 July 16:00 - 16:30 UTC & 6.9 & 212 & 8.8 \\
\hline IOP 4 - Trial 2 & 9 July 18:00 - 18:30 UTC & 7.9 & 197 & -6.3 \\
\hline IOP 4 - Trial 3 & 9 July 20:00 - 20:30 UTC & 7.9 & 199 & -8.3 \\
\hline
\end{tabular}



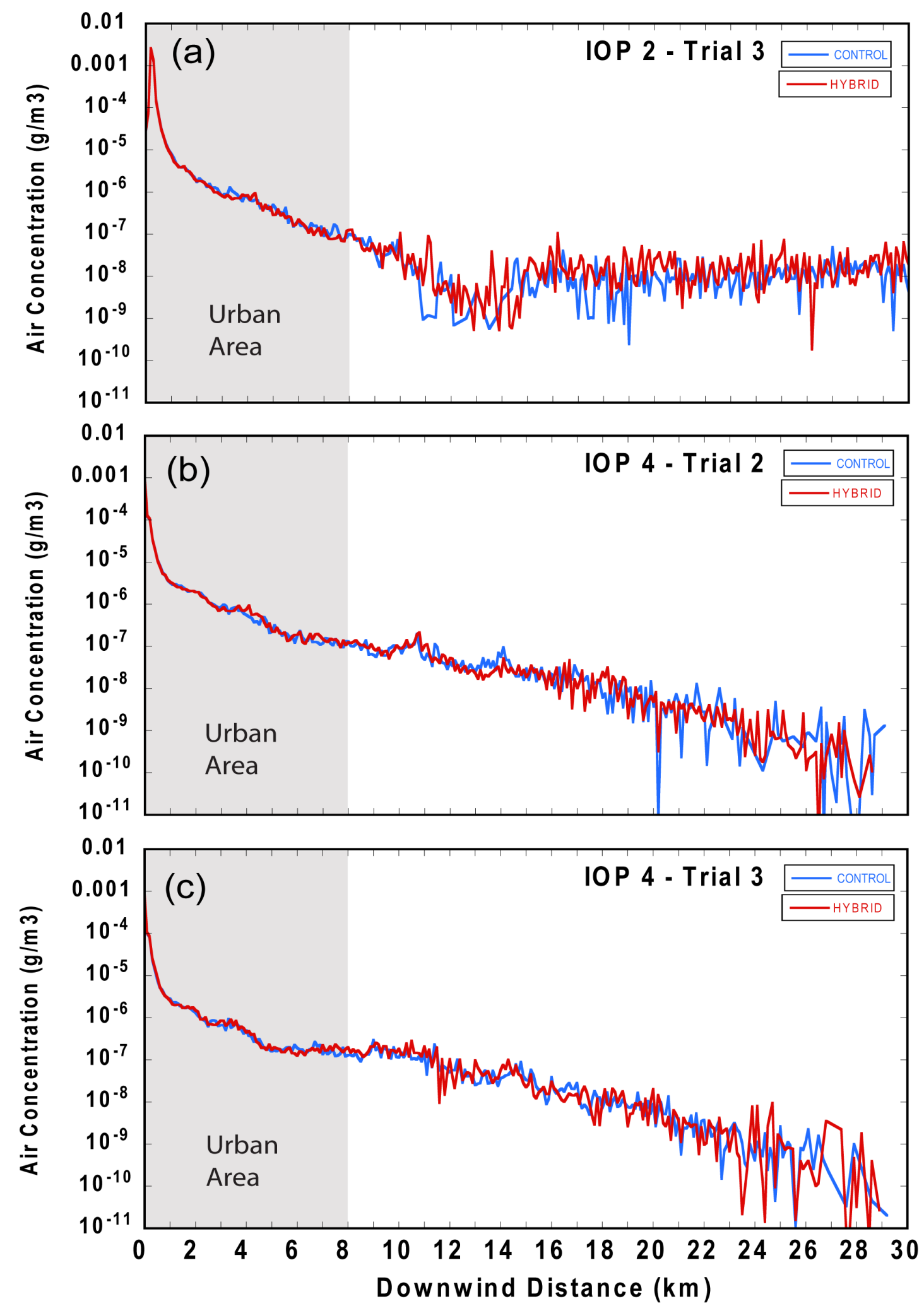

Figure 19. Comparison of CONTROL (blue) and HYBRID (red) centerline air concentration (g/m3) for (a) IOP 2 - Trial 3 release, (b) IOP 4 - Trial 2, and (c) IOP 4 - Trial 3 release. 
We conclude that the NASADATA surface data generally has a marginal impact on rural air concentrations that are well downwind of an urban release location though the impact is small for most of the dispersion test cases. However, in one circumstance, NASADATA surface data produces much different predicted air concentrations. It should be noted that this test case is not definitive as the effects of NASADATA surface data could be more significant for longer downwind distances and/or different seasons. 


\section{Summary of Evaluation Study Results}

Based on the evaluation study for the JU2003 case study, the following conclusions are made:

- A systematic difference in GSFC/SSC roughness lengths for rural land use is observed over the Oklahoma City research domain, with CONTROL values predominantly higher than NASA satellite derived values by around 0.05 to $0.1 \mathrm{~m}$ for crop and grassland and up to 0.45 $\mathrm{m}$ for deciduous forest land use. The typical difference between CONTROL and GSFC/SSC urban roughness lengths is between -0.2 to $0.5 \mathrm{~m}$ with CONTROL values predominately larger.

- Using GSFC/SSC surface characteristic values derived from NASA satellite data decreases simulated near surface wind speeds in rural areas by around $0.25 \mathrm{~m} / \mathrm{s}$ and increases surface layer wind speeds at heights between $15 \mathrm{~m}$ and $130 \mathrm{~m}$ by 0.25 to $0.75 \mathrm{~m} / \mathrm{s}$. Simulated near surface wind speeds in urban areas are significantly influenced by using GSFC/SSC surface roughness and displacement height values. CONTROL run urban wind speeds below a height of $10 \mathrm{~m}$ are frequently 0.5 to $1.0 \mathrm{~m} / \mathrm{s}$ less than those generated based on NASADATA surface data. Simulated wind speeds at heights between 10 and $130 \mathrm{~m}$ often increase by a few meters per second when using GSFC/SSC-derived surface data.

- Different statistical metrics of dispersion prediction skill indicate comparable performance between CONTROL and NASADATA runs. Runs based on CONTROL default surface parameter values provided the best dispersion results based on FAC2/5/10 and MG while NASADATA runs performed better based on NMSE and FB. The lack of consistency between these statistical metrics implies there is no clear better source of surface data parameters for this dispersion evaluation study and that both sets of runs exhibit the same general level of dispersion prediction skill.

- CONTROL run plumes are generally wider than NASADATA plumes by around $50 \mathrm{~m}$ due to the lower near surface wind speeds and greater surface stress induced diffusion resulting from the differences in surface characteristic values.

- Predicted peak air concentrations are highly sensitive to surface roughness and displacement height values with CONTROL run peak concentrations between 35 and 49\% lower than NASADATA peak simulated concentrations.

- Rural centerline air concentrations well downwind of an urban release location are marginally sensitive to choice of surface roughness data with most CONTROL and NASADATA prediction differences within 10\%. One dispersion test case examined demonstrated a particular sensitivity to roughness data and warrants additional analysis to fully understand. 
- The CONTROL runs in this evaluation study use surface characteristics derived from OKC building data that have been shown to give excellent results for JU2003 dispersion studies (Delle Monache 2009). Therefore, the NASADATA runs are being compared against a model configuration already shown to perform exceedingly well for the JU2003 test cases. The comparable dispersion prediction skill shown by the CONTROL and NASADATA runs support the conclusion that GSFC and SSC have developed a robust methodology for determining surface characteristics from NASA satellite data. 


\section{Recommendations for Future Work}

The results in this report provide an initial evaluation of the impacts of GSFC/SSC methods for determining surface roughness and displacement heights from NASA satellite data on dispersion modeling. Evaluation statistics from the JU2003 dispersion test cases indicate that the use of GSFC/SSC surface roughness values produces dispersion results that are comparable to predictions made using surface roughness values calculated from building data. However, the JU2003 evaluation results presented in this report are limited only to a single type of urban environment and are based on comparisons to sensor data relatively close to the atmospheric release location. Additional evaluation of the NASA surface data is warranted to fully understand the environments and scenarios where these data are likely to provide the greatest value.

Further data evaluation studies are needed in urban centers with building geometries and densities different than Oklahoma City to confirm the results from this project. In addition, work needs to be performed to further evaluate NASA surface data influence on dispersion calculations in rural regions and over larger spatial domains, where the impact of seasonal surface characteristics variation on dispersion modeling is likely to be important.

Due to the limited availability of dispersion field study data sets, future surface data evaluation studies may need to focus on evaluation of wind profiles versus dispersion concentration in order to investigate data sensitivity over multiple seasons and locations. NASA satellite derived surface products have the potential to improve the accuracy of numerical weather prediction (NWP) models such as the widely used Weather Research and Forecast (WRF) model. Skillful forecasting of wind flow is critical in producing accurate predictions of atmospheric transport and diffusion. Incorporation of enhanced surface characteristic data, including spatially distributed surface roughness lengths (which have a large influence on nearsurface winds) has the potential to significantly improve NWP forecast skill. 


\section{Acknowledgments}

We are grateful to NASA for providing the funding for this project (grant number NNA07CA13I). The authors wish to thank the following agencies responsible for collecting and archiving the Joint Urban 2003 data used in this study: NOAA/ARL/FRD, VOLPE, LBNL, WSU, UU, DPG, ANL, and PNNL. We thank Julie Lundquist of the University of Colorado for writing the project proposal and for acting as the LLNL lead during the initial phase of the project. We also wish to thank Ernie Arnold and Akshay Gowardhan of the Lawrence Livermore National Laboratory for their technical assistance throughout the duration of this project. This work was performed under the auspices of the U.S. Department of Energy by Lawrence Livermore National Laboratory under Contract DE-AC52-07NA27344. 


\section{References}

Al-Jiboori, M. H., Fei, H., 2005. Surface Roughness around a 325-m Meteorological Tower and Its Effect on Urban Turbulence. Advances in Atmospheric Sciences, 22(4): 610-620.

Allwine, K.J., Leach, M.J., Stockham, L.W., Shinn, J.S., Hosker, R.P., Bowers, J.F., Pace, J.C., 2004. Overview of Joint Urban 2003dan atmospheric dispersion study in Oklahoma City. In: Symposium on Planning, Nowcasting and Forecasting in the Urban Zone. American Meteorological Society, Seattle, WA CDROM, J7.1.

Allwine, K.J., Flaherty, J.E., 2006. Joint Urban 2003: Study Overview and Instrument Locations. PNNL-15967, Pacific Northwest National Laboratory, Richland, WA.

Arya, S. P., 1998. Introduction to Micrometeorology. San Diego, Academic Press.

Blonski, S., Berglund, J., Spruce, J.P., Holland, R., McKellip, R., Jasinski, M., Borak, J., Lundquist, J., 2007. Evaluation of a Potential for Enhancing the Decision Support System of the Interagency Modeling and Atmospheric Assessment Center with NASA Earth Science Research Results, \#20070011487, 18pp.

Borak, J.S., Jasinski, M., Crago. R., 2005. Time series vegetation aerodynamic roughness fields estimated from MODIS observations. Agricultural and Forest Meteorology 135, 252-268.

Borak, J.S., Jasinski, M.F., 2009. Effective interpolation of incomplete satellite-derived leaf-area index time series for the continental United States. Agricultural and Forest Meteorology 149, 320332.

Bou-Zeid, E., Parlange, M.B., Meneveau, C., 2007. On the Parameterization of Surface Roughness at Regional Scales. Journal of the Atmospheric Sciences 64(1): 216-227.

Burian, S., San, W.S., Brown, M., 2005. Morphological Analyses Using 3D Building Databases: Oklahoma City. Report LA-UR-05-1821. Los Alamos National Laboratory, Los Alamos, NM.

Cao, M., Z. Lin, Y. Shao, Li, A., 2009. Wind Profiles and Roughness Lengths Over Beijing City. $7^{\text {th }}$ International Conference on Urban Climate, Yokohama, Japan, 29 June-3 July.

Chan, S.T., Sugiyama, G., 1997. A new model for generating mass-consistent wind fields over continuous terrain. In: Preprint, ANS Sixth Topical Meeting on Emergency Preparedness and Response, San Francisco, CA, pp. 375-378.

Chang, J., Hanna, S., 2004. Air quality model performance evaluation. Meteorology and Atmospheric Physics Vol. 87 (1-3): 167-196.

Chang, S., Huynh, G., 2007. A Comparison of Roughness Parameters for Oklahoma City from Different Evaluation Methods. $7^{\text {th }}$ Symposium on the Urban Environment, American Meteorological Society, San Diego, California, 10-13 September. 
Cimorelli, A.J., Perry, S.G., Venkatram, A., Weil, J.C., Paine, R.J., Wilson, R.B., Lee, R.F., Peters, W.D., Brode, R.W., 2005. AERMOD: a dispersion model for industrial source applications. Part I: general model formulation and boundary layer characterization. Journal of Applied Meteorology 44, 682-693.

Davenport, A. G., Grimmond, C.S.B., Oke, T.R., Wieringa, J., 2000. Estimating the roughness of cities and sheltered country. $12^{\text {th }}$ Conference on Applied Climatology, American Meteorological Society, Asheville, North Carolina, 8-12 May.

Delle Monache, L., Weil, J., Simpson, M., Leach, M., 2009. A new urban boundary layer and dispersion parameterization for the LLNL modeling system: Tests with the Joint Urban 2003 data set. Atmospheric Environment, 43, 5807-5821.

Dong, Z., Gao, S., Fryear, D., 2001. Drag coefficients, roughness length and zero-plane displacement height as disturbed by artificial standing vegetation. Journal of Arid Environments 49,485-505.

Faulkner, W.B., Shaw, B.W., Grosch, T., 2008. Sensitivity of two dispersion models (AERMOD and ISCST3) to input parameters for a rural ground level area source. Journal of the Air and Waste Management Association 58: 1288-1296.

Flaherty, J.E., Lamb, B., Allwine, K.J., Allwine, E., 2007. Vertical Tracer Concentration Profiles Measured during the Joint Urban 2003 Dispersion Study. J. Appl. Meteor. Climatol., 46, 20192037.

Fry, J., Xian, G., Jin, S., Dewitz, J., Homer, C., Yang, L., Barnes, C., Herold, N., Wickham, J., 2011. Completion of the 2006 National Land Cover Database for the Conterminous United States, PEERS, Vol. 77(9):858-864.

Grimmond C.S.B., Oke, T.R., 1999. Aerodynamic properties of urban areas derived from analysis of surface form. Journal of Applied Meteorology, 38, 1262-1292.

Grosch, T.G., 1999. Sensitivity of the AERMOD Air Quality Model to the Selection of Land Use Parameters. Presented at the Seventh International Conference on Air Pollution: AIR POLLUTION 99, Palo Alto, CA, July 27-29.

Hanna, S.R., Strimaitis, D.G., Chang J.C., 1991. Hazard response modeling uncertainty (a quantitative method), Vol. II: evaluation of commonly-used hazardous gas dispersion models. AFESC Contract No. FO8635-89-C- 0136, H. Q. AFESC/RDVS, Tyndall AFB, Florida.

Hanna, S.R., Chang, J.C., 1992. Boundary layer parameterisations for applied dispersion modelling over urban areas. Bound.-Layer Meteor.,58, 229-259.

Harris T.R., Smith, J.N., Smith, R.J., Hancock, N.H., 1996. Vertical Dispersion of Emissions from Ground Level Sources: A comparison of the Lagrangian and Gaussian Models, Conference on Engineering in Agriculture and Food Processing, Gatton, Queensland. 
Jackson, P. S., 1981. On the displacement height in the logarithmic velocity profile. J. Fluid Mech., $111,15-25$.

Jasinski, M., Borak, J., Crago, R., 2005. Bulk Surface Momentum Parameters for Satellite Derived Vegetation fields. Agricultural and Forest Meteorology 133, 55-68.

Kirk-Davidoff, D.B., Keith, D.W., 2008. On the climate impact of surface roughness anomalies J. Atmos. Sci., 65, 2215-34.

Long, G.E., Cordova, J.F., Tanrikulu, S., 2004. An Analysis of AERMOD Sensitivity to Input Parameters in the San Francisco Bay Area. In Proceedings of the 13th Joint Conference on the Applications of Air Pollution Meteorology with the Air \& Waste Management Association; A\&WMA: Pittsburgh, PA, pp 203-206.

NASA Landsat Program, 2003. Landsat ETM+ scene L71008058_05820031026, SLC-Off, USGS, Sioux Falls, 10/26/2003.

Nasstrom, J.S., Sugiyama, G., Leone Jr., J.M., Ermak, D.L., 2000. A real-time atmospheric dispersion modeling system. In: Preprint, Eleventh Joint Conference on the Applications of Air Pollution Meteorology. American Meteorological Society, Boston, MA, pp. 84-89.

Nasstrom, J.S., Sugiyama, G., Baskett, R.L., Larsen, S.C., Bradley, M.M., 2007. The National Atmospheric Release Advisory Center modelling and decision-support system for radiological and nuclear emergency preparedness and response. International Journal of Emergency Management 4, 524-550.

Perry, S.G., 1992. A dispersion model for sources in complex topography. Part I: technical formulations. Journal of Applied Meteorology, 31, 633-645.

Raupach M.R., Thom, A.S., 1981. Turbulence in and above Plant Canopies. Annual Review of Fluid Mechanics 13, 97-129.

Sawyer, P., 2007. Atmospheric Dispersion Model Validation in Low Wind Conditions. National Security Technologies, LLC. DOE/NV/25946-277.

Schnelle, K.B., Dey, P.R., 1999. Atmospheric Dispersion Modeling Compliance Guide (1st Edition ed.). McGraw-Hill Professional. ISBN 0-07-058059-6.

Simpson, M., Raman, S., Lundquist, J.K., Leach, M., 2007. A study of the variation of urban mixed layer heights. Atmospheric Environment 41, 6923-6930.

Smith R. J., 1993. Dispersion of odours from ground level agricultural sources. Journal of Agricultural Engineering Research 54, 187-200.

Stull, R.B., 1993. An Introduction to Boundary Layer Meteorology. Kluwer Academic Publishers, Dordrecht, The Netherlands. 
Sugiyama, G., Chan, S.T., 1998. A new meteorological data assimilation model for real-time emergency response. Preprint, Tenth Joint Conference on the Applications of Air Pollution Meteorology, American Meteorological Society, Boston, MA, 285-289.

Sugiyama, G., J. Nasstrom, R. Baskett, and M. Simpson, 2010: National Atmospheric Release Advisory Center (NARAC) Capabilities for Homeland Security, Fifth International Symposium on Computational Wind Engineering (CWE2010), Chapel Hill, North Carolina, USA May 23-27, 2010.

Tennekes, H., 1973. The logarithmic wind profile. J. Atm. Sci., 234-238.

USEPA, 2001. Appendix W to Part 51 - Guideline on Air Quality Models, United States Environmental Protection Agency, USA.

van Ulden, A.P., Holtslag, A.A.M., 1985. Estimation of atmospheric boundary layer parameters for diffusion applications. J. Climate Appl. Meteor., 1196-1207.

VicEPA, 2000. Ausplume Gaussian Plume Dispersion Model - Technical Users 122 Manual, Victorian Environment Protection Authority, Victoria.

Wever, N., 2012. Quantifying trends in surface roughness and the effect on surface wind speed observations, J. Geophys. Res., 117, D11104, doi:10.1029/2011JD017118.

Wieringa, J., 1992. Updating the Davenport roughness classification. Journal of Wind Engineering and Industrial Aerodynamics, Vol.41, pp, 357-368.

Yadav, A. K., Sharan, M., 1996. Statistical evaluation of sigma schemes for estimating dispersion in low wind conditions. Atmos. Environ., 30, 2595-2606.

Zhu, P., 2008. Impact of land-surface roughness on surface winds during hurricane landfall. $Q$. J. R. Meteorol. Soc. 134: 1051-1057. 


\section{Acronyms}

ADAPT Atmospheric Data Assimilation and Parameterization Techniques

ARM Atmospheric Radiation Measurement

ATD Atmospheric Transport and Diffusion

CART Cloud and Radiation Testbed

CBD Central business district

CFD Computational fluid dynamics models

CONUS Contiguous United States

DOE Department of Energy

DHS Department of Homeland Security

DST Decision Support Tool

GSFC Goddard Space Flight Center

IMAAC Interagency Modeling and Atmospheric Assessment Center

IGBP International Geosphere-Biosphere Programme

IHOP International $\mathrm{H} 2 \mathrm{O}$ Project

IOP Intensive observation periods

ISL Inertial sublayer

ISS Integrated System Solution

JU2003 Joint Urban 2003

LAI Leaf area index

LIDAR Light Detection and Ranging

LLNL Lawrence Livermore National Laboratory

LODI Lagrangian Operational Dispersion Integrator

LULC Land use / Land cover

MODIS Moderate Resolution Imaging Spectroradiometer

NARAC National Atmospheric Release Advisory Center

NASA National Aeronautics and Space Administration

NED National Elevation Dataset

NGA National Geospatial-Intelligence Agency

NLCD National Land Cover Database

NWP Numerical weather prediction

OKC Oklahoma City, OK

ORNL Oak Ridge National Laboratory

ROSES Research Opportunities in Space and Earth Science

RSL Roughness sublayer

SAIC Science Applications International Corporation

SRTM Shuttle Radar Topography Mission

UCL Urban canopy layer

VTMX Vertical Transport and Mixing Experiment 


\section{Appendix}

Table A-1 NARAC/IMAAC look-up table for default surface roughness lengths and displacement heights for specific land use categories. Default building height values for urban land when measured building height data are unavailable are also shown.

\begin{tabular}{|c|c|c|c|c|}
\hline NLCD & Description & $\begin{array}{l}\text { Roughness } \\
\text { Length (m) }\end{array}$ & $\begin{array}{c}\text { Displacement } \\
\text { Height }(\mathrm{m})\end{array}$ & $\begin{array}{c}\text { Building } \\
\text { Height* }(\mathrm{m})\end{array}$ \\
\hline 11 & Open Water & 0.01 & 0 & 0 \\
\hline 12 & Perennial Ice / Snow & 0.012 & 0 & 0 \\
\hline 21 & Developed, Open Space & 0.2 & 0.5 & 2.5 \\
\hline 22 & Developed, Low Intensity & 0.35 & 2.5 & 3.0 \\
\hline 23 & Developed, Medium Intensity & 0.45 & 5 & 6.0 \\
\hline 24 & Developed, High Intensity & 0.6 & 7.5 & 9.0 \\
\hline 31 & Barren Land & 0.2 & 0 & 0 \\
\hline 32 & Unconsolidated Shore (C-CAP only) & 0.2 & 0 & 0 \\
\hline 41 & Deciduous Forest & 0.5 & 7 & 0 \\
\hline 42 & Evergreen Forest & 0.5 & 7 & 0 \\
\hline 43 & Mixed Forest & 0.5 & 7 & 0 \\
\hline 51 & Dwarf Scrub (Alaska Only) & 0.06 & 2 & 0 \\
\hline 52 & Shrub / Scrub & 0.06 & 2 & 0 \\
\hline 71 & Grassland / Herbaceous & 0.15 & 0 & 0 \\
\hline 72 & Sedge herbaceous (Alaska Only) & 0.15 & 0 & 0 \\
\hline 73 & Lichens (Alaska Only) & 0.15 & 0 & 0 \\
\hline 74 & Moss (Alaska Only) & 0.15 & 0 & 0 \\
\hline 81 & Pasture / Hay & 0.15 & 0.5 & 0 \\
\hline 82 & Cultivated Crops & 0.1 & 0.5 & 0 \\
\hline 90 & Woody Wetlands & 0.3 & 3.5 & 0 \\
\hline 91 & Palustrine Forested Wetland (C-CAP only) & 0.3 & 3.5 & 0 \\
\hline 92 & Palustrine Scrub / Shrub (C-CAP only) & 0.06 & 2.5 & 0 \\
\hline 93 & Estuarine Forested Wetlands (C-CAP only) & 0.3 & 3.5 & 0 \\
\hline 94 & Estuarine Scrub / Shrub (C-CAP only) & 0.06 & 2.5 & 0 \\
\hline 95 & Emergent Herbaceous Wetland & 0.2 & 0.5 & 0 \\
\hline 96 & Palustrine Emergent Wetland (C-CAP only) & 0.2 & 0.5 & 0 \\
\hline 97 & Palustrine Emergent Wetland (C-CAP only) & 0.2 & 0.5 & 0 \\
\hline 98 & Palustrine Aquatic bed (C-CAP only) & 0.2 & 0.5 & 0 \\
\hline 99 & Estuarine Aquatic bed (C-CAP only) & 0.2 & 0.5 & 0 \\
\hline
\end{tabular}

* Building heights from the land use table are only used when measured building height data are unavailable. 